\title{
Marcas militares sobre producciones latericias en Hispania. Nuevas consideraciones sobre su origen y difusión
}

\author{
Ángel Morillo ${ }^{1}$ \\ Universidad Complutense de Madrid \\ amorillo@ghis.ucm.es \\ Javier SALIDo DomíngueZ \\ Escuela Española de Historia y Arqueología en Roma-CSIC \\ pjaviers@hotmail.com
}

Recibido: 11 de marzo de 2013

Aceptado: 8 de julio de 2013

\section{RESUMEN}

En este trabajo se analizan las marcas militares sobre producciones latericias en Hispania, principalmente vinculadas a dos cuerpos legionarios (legio VII gemina y legio X gemina), estacionados en León y Rosinos de Vidriales, respectivamente, además de varias unidades auxiliares (ala Parthorum, cohors I Celtiberorum y ala II Flavia), acantonadas en Herrera de Pisuerga, Cidadela y Rosinos de Vidriales, respectivamente. Se abordan asimismo cuestiones como la hipotética adscripción militar de algunas marcas como las estampillas de la legio IIII Macedonica halladas en Clunia y Manigoto (Pinhel). El análisis de este material nos permite en último término plantear la cuestión del origen de las marcas militares sobre material latericio en la Península Ibérica, así como la identificación de nombres propios de trabajadores asociados a los de las unidades militares, posiblemente vinculados al proceso productivo de los talleres establecidos por las autoridades castrenses.

Palabras clave: Arqueología militar. Campamentos romanos. Aprovisionamiento. Material constructivo. Sellos.

\section{Roman military bricks and tiles stamps in Spain. Reflections on the origin and spread}

\begin{abstract}
In this paper, we present an overview of Roman military bricks and tiles stamps in Hispania, mainly belonging to two legionary units (legio VII gemina and legio X gemina), stationed at León and Rosinos de Vidriales respectively, and others stamped by auxiliary units (ala Parthorum, cohors I Celtiberorum and ala II Flavia), stationed at Herrera de Pisuerga, Cidadela and Rosinos de Vidriales respectively. We also analyze an assemblage of stamps of probable military origin of legio IIII Macedonica found at Clunia and Manigoto (Pinhel). The study of this material provide value information about the origin of the practice of stamping bricks in the Iberian Peninsula, and the identification of names of brickmakers associated with military units, possibly related to the production of workshops established under the military control.
\end{abstract}

1 El presente trabajo se ha elaborado en el marco del Proyecto de I+D HAR2011-24095: Campamentos y territorios militares en Hispania, dirigido por A. Morillo, concedido por el Ministerio de Ciencia e Innovación el 1 de enero de 2012. 
Key words: Military archaeology. Roman forts. Supplying. Constructive material. Bricks and tiles stamps.

Sumario: 1. Introducción. 2. Los sellos de las unidades militares asentadas en Hispania. 3. El origen del sellado militar en Hispania. 4. Producción, dispersión y finalidad de los sellos militares hispanos. 5. Consideraciones finales.

\section{Introducción}

Dentro de los estudios arqueológicos vinculados a la producción y aprovisionamiento del ejército romano, las estampillas militares han sido una de las cuestiones que mayor atención ha recibido por parte de la investigación. Las marcas sobre tejas y ladrillos se han empleado para intentar localizar talleres, áreas productivas y posibles circuitos de comercialización, además de constatar la presencia y los movimientos de tropa, así como el territorio bajo jurisdicción de las diferentes unidades. Las novedades que se han dado a conocer durante los últimos años nos permiten avanzar algunas consideraciones sobre los sellos militares sobre material latericio, en particular sobre el origen de esta costumbre en las provincias hispanas y la dimensión real que alcanzó en las mismas.

Han sido las provincias septentrionales del Imperio donde mayor desarrollo ha conocido el estudio de las producciones latericias con marcas militares. El estacionamiento en estas regiones (Britannia, Germania, Gallia, Raetia, Noricum, Dacia, Pannonia, Moesia) de la mayor parte de las tropas romanas a partir de Augusto y el modelo de romanización de las mismas, dentro del cual el elemento militar juega un papel determinante, justifica esta situación, además de la propia evolución de la arqueología militar, mucho más avanzada en los países de Europa Occidental. Análisis como los de McWhirr (ed.), ${ }^{2}$ Brodribb ${ }^{3}$ y Le Bohec ${ }^{4}$ han ido perfilando los tipos, la epigrafía y las funciones del material sellado por el ejército. Los estudios regionales sobre provincias como Dacia, ${ }^{5}$ Britania, ${ }^{6}$ Recia, ${ }^{7}$ Mesia ${ }^{8}$ y Panonia, ${ }^{9}$ o la amplia bibliografía sobre los sellos de unidades o campamentos concretos, han ido ampliando el catálogo de marcas latericias militares. Las recientes monografías de $\operatorname{Brandl}^{10} \mathrm{y}$, especialmente de Kurzmann, ${ }^{11}$ que constituye un buen estado de la cuestión, reflejan a la perfección nuestros conocimientos y carencias.

A diferencia de estas regiones septentrionales del Imperio, donde la primera producción latericia fue sin duda militar, ${ }^{12}$ el sellado de tejas y ladrillos en la antigua

\footnotetext{
2 MCWhirr (ed.) 1979.

3 BRODRIBB 1987.

4 Le BoHeC 1992.

5 MACREA 1945-1947.

6 McWhirr 1979; Hassall 1979; Warry 2010.

7 Spitzlberger 1968.

8 Radulescu 1974; Gudea 2001.

9 LÖRINZ 1994.

10 BRandL 1999.

11 Kurzmann 2006.

12 DarVill - McWhirr 1984, 247.
} 
Hispania presenta rasgos diferenciados. A nivel general, es mucho menos numeroso, debido principalmente a la reducida presencia del ejército romano a partir del periodo flavio, momento precisamente a partir del cual la marca militar se regulariza y se extiende el hábito epigráfico. ${ }^{13}$ La mayor parte de la información procede de contados campamentos, entre los que destacan León, ${ }^{14}$ Cidadela, ${ }^{15}$ Rosinos de Vidriales ${ }^{16} \mathrm{y}$ Herrera de Pisuerga. ${ }^{17}$ Se han acometido contados estudios de conjunto. En 1999 Le Roux publica un breve análisis donde da a conocer los materiales disponibles, centrándose en algunas cuestiones productivas, así como en los problemas que plantea la difusión del material militar. ${ }^{18}$ En su reciente publicación Kurzmann dedica un capítulo a las producciones militares hispanas, aunque su bibliografía presenta ciertas lagunas y confusiones, lo que relativiza su aportación. ${ }^{19}$ Algunas reflexiones generales sobre la cuestión se han publicado en análisis de conjunto sobre la producción y el abastecimiento militar en Hispania. ${ }^{20}$

\section{Los sellos de las unidades militares asentadas en Hispania}

La aparición de los primeros sellos militares sobre material latericio hispano tiene lugar durante el periodo julioclaudio, momento en que se verifica una gran concentración de unidades militares en suelo peninsular, de al menos tres legiones (legio IIII Macedonica, legio VI victrix y legio X gemina) y sus correspondientes auxilia. ${ }^{21}$ Sin embargo, la mayor incidencia de este fenómeno tiene lugar a partir del periodo flavio, unido al establecimiento de la legio VII gemina en León, y la creación de una red de fuertes auxiliares en el noroeste peninsular como Bande, Herrera de Pisuerga, Rosinos de Vidriales y Cidadela. Presentamos a continuación el repertorio de unidades que sellaron sus producciones durante su estancia en la Península Ibérica.

\subsection{Legio X gemina}

La legio X gemina deriva de una famosa legión de César. En este caso su presencia parece remontarse a las primeras fases de las guerras cántabras, actuando junto a las legiones V alaudae y VI victrix en las campañas contra los astures del 25 a.C., por lo que parece ya desde un principio asignada al ejército de la Ulterior, que tiene a su cargo el frente occidental. A través de las emisiones monetales sabemos que sus veteranos participan junto con los de la legio $V$ en la fundación de Emerita, inmediata-

\footnotetext{
13 Le Roux 1999, 111.

14 García y Bellido 1970; Liz Guiral - Amaré 1993.

15 CaAmaño 1989; Carlson-Brandt 2011.

16 Wahl 1984; Martín Valls et alii 2002.

17 PÉrez González 1996.

18 Le Roux 1999.

19 Kurzmann 2006, 99-108.

20 Morillo 2006; ID. 2008a.

21 Morillo 2002.
} 
mente después de la campaña del $25 \mathrm{y}$, junto con los de la IV Macedonica y VI victrix, en la deductio que da origen a la colonia de Caesaraugusta, en torno al 15-14 a.C. ${ }^{22}$

Tras la conquista de los territorios septentrionales, se hace cargo conjuntamente con la Legio VI victrix de la vigilancia y el control de la región astur, donde permanece asentada hasta el 63 d.C., año en que es trasladada por Nerón al campamento de Carnuntum, en Panonia, para sustituir a la legio XV Apollinaris. En el año 68 d.C. regresa brevemente a Hispania por decisión de Galba, quien la sustituye en Carnuntum por la nueva legio VII "Galbiana". ${ }^{23}$

Adscrita al partido de Vitelio, se ocupa de la defensa de la Bética, amenazada por el gobernador de Mauritania, que mostraba simpatías por Otón (Tácito, Hist. II, 58). Durante el año 69 d.C., instigada por la legio I adiutrix y de acuerdo con la legio VI, reconoce como emperador a Vespasiano. En ese año parte con el resto del exercitus Hispanicus hacia Germania Inferior, aunque Ritterling opina que permaneció unos meses más que sus compañeras en la Península. ${ }^{24}$ Tras una breve estancia en un hipotético campamento ubicado en Arenacum, fue instalada en Noviomagus, para partir hacia Panonia a comienzos del siglo II d.C.

Contamos con numerosos testimonios epigráficos fechables durante su estancia en Hispania repartidos por todo el territorio peninsular, aunque la principal concentración se registra en el territorio astur augustano. ${ }^{25}$

Asentada en Astorga desde el final de las guerras cántabras, hacia el 15/20 d.C. abandona este recinto militar ${ }^{26}$ trasladándose a un nuevo campamento construido pocos kilómetros más al Sur, en un emplazamiento cercano a los distritos mineros de los Montes de León, ubicado en la localidad de Rosinos de Vidriales (Zamora), identificada con la antigua Petavonium. El establecimiento de la Legión X en este lugar está avalado por la presencia de un gran recinto rectangular con esquinas redondeadas, de unas 17,5 ha, que parece contar con un potente muro realizado con bloques de cuarcita y argamasa y un doble foso en algunos de sus lados, además de diversos testimonios epigráficos sobre lápidas y tégulas. ${ }^{27} \mathrm{El}$ conocimiento de este acantonamiento se ve entorpecido por la presencia de un campamento superpuesto, que fue construido a fines del siglo I por una unidad auxiliar, el ala II Flavia Hispanorum civium Romanorum. ${ }^{28}$

La fecha en que tiene lugar el estacionamiento de la legio X gemina en Rosinos dista mucho de estar aclarada convenientemente, ya que el registro arqueológico correspondiente al periodo más antiguo permanece por el momento inédito. Los investigadores dataron en un primer momento la fundación del campamento durante las

22 cf. Morillo - García Marcos 2000, 592-594.

23 Ritterling 1925, cols. 1679-1681; García y Bellido 1961, 126-128; Roldán 1974, 206-207 y 451-454; RodRíGUEZ GONZÁLEZ 2001, 291-305.

24 RITTERLING 1925, col. 1681.

25 RoLdÁN 1974, 206-207 y 451-454.

26 Morillo 1999, 335; Morillo - García Marcos 2000, 598.

27 Martín Valls et alii 1975; Wahl 1984; Carretero - Romero Carnicero 1996, 9-21; Carretero 2006 , $171-177$

28 CARretero 2000. 
Guerras Cántabras. ${ }^{29}$ Carretero y Romero Carnicero lo retrasan hasta el 20/15 a.C., una vez terminada la contienda. ${ }^{30}$ Sin embargo, estos mismos autores ya señalan que el patrón material más antiguo es en su mayoría posterior al cambio de Era y su mayor concentración arranca del reinado de Tiberio. Recientemente se ha señalado que el registro conocido de la legio X gemina, documentado a través de dos sondeos y datado entre el 10 a.C. y el 70 d.C. se podría dividir en dos subfases, una tardoaugusteatiberana y otra claudio-neroniana. ${ }^{31}$

Por nuestra parte, y a reserva que nuevas publicaciones pudieran modificar este panorama, planteamos que la fundación del recinto militar de Rosinos debe retrasarse hasta el periodo tiberiano, coincidiendo con la partida de Astorga de los efectivos de la legio X gemina. Sin embargo, no podemos descartar completamente la convivencia de los recintos campamentales de Astorga y Rosinos durante algunos años, aunque esta hipótesis implicaría la existencia de una fase constructiva más antigua en el recinto militar de Rosinos, que hasta hoy no conocemos. ${ }^{32}$

Por otra parte, la petrificación de estructuras defensivas en recintos militares romanos no se documenta hasta mediados del siglo I d.C. y no se aplica a campamentos legionarios hasta época flavia, momento de reedificación de numerosos recintos en Germania tras la revuelta bátava de Civilis.$^{33}$ La existencia de una muralla de piedra en Rosinos constituiría un unicum en contextos augusteos o julioclaudios, por lo que debemos postular al menos una segunda fase constructiva en dicho acantonamiento, a la que correspondería la muralla pétrea. A favor de esta interpretación hablaría asimismo el carácter estrictamente regular del recinto defensivo, planta que aún no ha alcanzado su pleno desarrollo en los campamentos renanos del periodo augusteo y que debe estandarizarse a partir de los reinados de Claudio y Nerón.

Las marcas legionarias de Rosinos, presentes en tan sólo 15 ejemplares, se constatan sobre tegulae (14) y ladrillos pedales (1) (Fig. 1). Se han documentado marcas de varias formas, si bien todas ellas presentan la misma fórmula epigráfica LXG, con o sin interpunciones, que responde al desarrollo L(egio) X G(emina). ${ }^{34}$ Casi todas se han realizado por estampación, ya que presentan sellos en relieve. Un único ejemplar muestra una marca realizada a mano alzada con un punzón, asociada a un nombre propio de un soldado: Rufus mil(es) L(egionis) X G(eminae) f(ecit), que se considera anterior a los sellos en relieve. ${ }^{35}$

Los investigadores no descartan que la legión pudiera haber sellado sus producciones con anterioridad a su primera salida de Hispania en el 63 d.C. ${ }^{36}$ Más verosímil parece que los materiales se daten posiblemente entre el 68 y el $69 / 70$ d.C., ${ }^{37}$ tras el retorno a la Tarraconense de esta unidad desde el limes danubiano y antes de su parti-

29 Martín VALls et alii $1975,6$.

30 Carretero - Romero Carnicero 1996, 10; Carretero 2006, 171.

31 Blázquez - CARretero 2006, 195, nota 1.

32 Morillo 2002, 84.

33 Jones 1975, 14-18; Johnson 1983, 250.

34 Martín Valls et alii 2002.

35 Martín VALLS et alii 2002, 148-150.

36 Martín Valls et alii 2002, 150.

37 WaHL 1984, 73-74. 

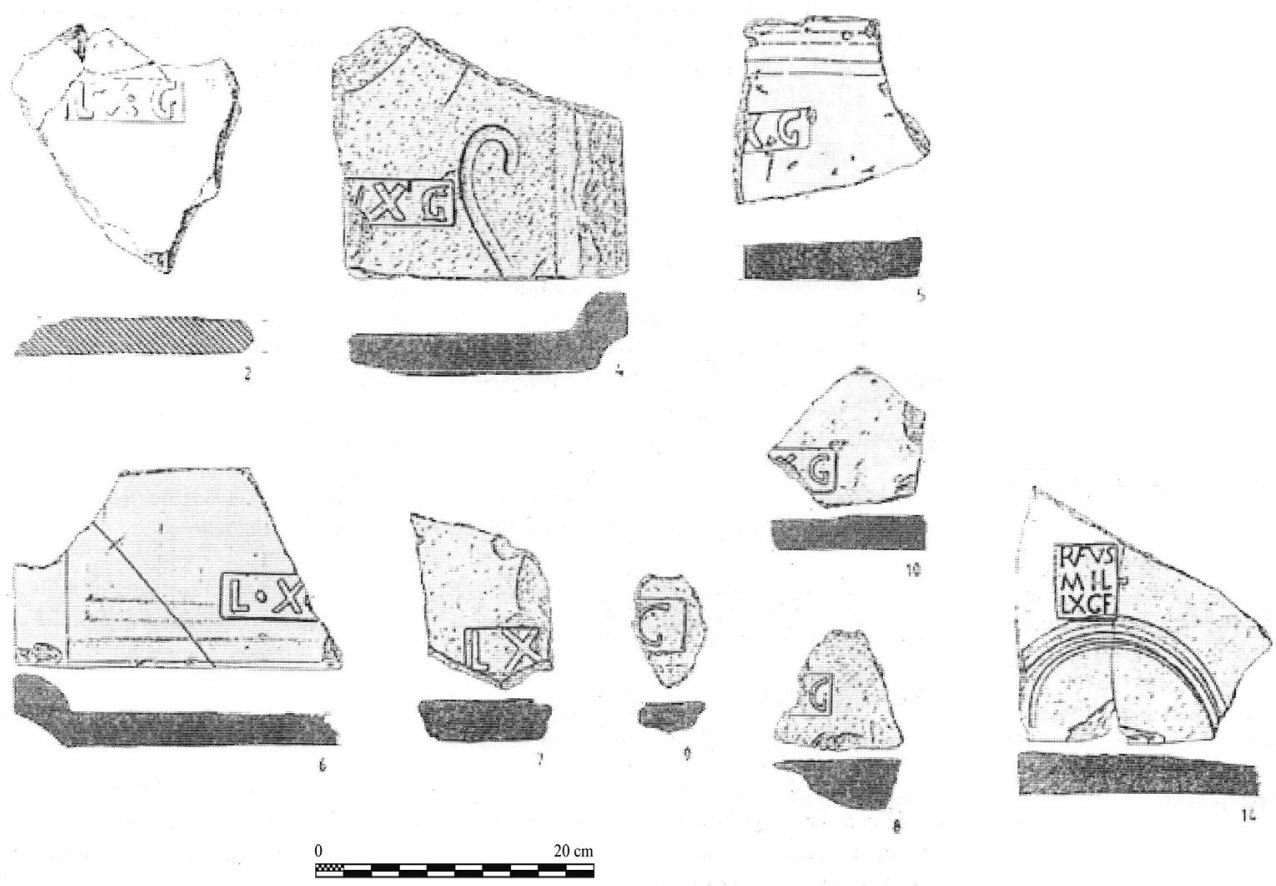

Fig. 1. Tejas militares de Rosinos de Vidriales con marca de la legio X Gemina. Imág.: Martín Valls - Romero - Carretero 2002, fig. 1 (con modificaciones).

da definitiva de la Península en el 69/70 d.C. Sin embargo, carecemos de dato alguno sobre el emplazamiento de esta legión durante los años 68-69 d.C. Aunque del pasaje de Tácito (Hist. II, 58) parece desprenderse su estancia en la Baetica durante algún tiempo, desconocemos si la legión se desplazó en su conjunto o tan sólo destacó algunas vexillationes, mientras el grueso de la unidad permanecía en otro lugar, tal vez en su antiguo campamento de Rosinos.

\subsection{Legio VII gemina}

Las producciones latericias selladas por la Legión VII Gémina son las más abundantes en el conjunto de Hispania. Existe una abundante bibliografía sobre la creación e historia de la legio VII gemina. ${ }^{38}$ La razón fundamental que explica el natalicio de la legio VII va a ser la necesidad de Galba, gobernador de la Tarraconensis, de contar con un ejército en el que apoyar su levantamiento contra Nerón. La unidad recibió

38 Ritterling 1925, col. 1630-1641; García y Bellido 1970b, 303-328; RoldÁn 1974, 201-204; LE Roux 1982, 151-153 e ID. 2000; Abascal 1986, 317-328; Rodríguez GonZÁlez 2001, 291-305; Palao 2006; Morillo - García Marcos 2006, 234-236; Morillo 2006a. 
el numeral VII, correlativo al de la única unidad presente en aquel momento en la Península, la VI victrix, su legión matriz. Gracias a dos de las lápidas descubiertas en Villalís ${ }^{39}$ conocemos la fecha exacta en la que la legio VII recibió sus insignias: el 10 de junio del año 68 d.C. (CIL II 2552 y 2554). En su primera etapa recibirá el apelativo de Galbiana (Tácito, Hist. II, 86 y III, 7,10, 21) en honor a su fundador, e Hispana, alusivo a su origen (Tácito, Hist. I, 6).$^{40}$ La Legión VII creada por Galba constituye de hecho el embrión de la futura VII gemina.

La unidad parte de Hispania acompañando a Galba. En octubre del 68 d.C. ya está operando en Roma, para posteriormente ser destinada al limes danubiano, concretamente a Carnuntum (Panonia). Tras la muerte de Galba toma partido por Otón, regresando de nuevo a Italia. Con Vitelio retorna brevemente al Danubio, desde donde apoya a Vespasiano, lo que la llevará a participar en la segunda batalla de Bedriacum (cerca de la actual Cremona) en octubre del 69 d.C. (Tácito, Hist. III, 22). La trascendencia de este episodio para la legio VII, que, según Tácito, perdió varios mandos y enseñas, ha llevado a numerosos investigadores a argumentar que, tras la mencionada batalla, la unidad debió quedar tan diezmada que le serían asignados efectivos procedentes de otra legión, portando a partir de este momento el epíteto de gemina (doble, acoplada). ${ }^{41}$ Pero dicha interpretación se basa en datos indirectos. No es descartable otra explicación que justifique el cognomen "gemina" que pasa a ostentar a partir de este momento, como el propio signo zodiacal bajo el que se produce su creación, geminis. ${ }^{42}$

Posteriormente es destinada a la Germania Superior, donde sabemos de su presencia, por las lápidas de los tribunos T. Staberius y C. Baburius, ambas fechadas en el 73/74 d.C., donde aparece ya con los epítetos gemina y felix (CIL VI 3538 y CIL XIII 5033 , respectivamente) y el hallazgo de varias tegulae donde aparece la unidad con el cognomen gemina en el importante centro alfarero de Rheinzabern (CIL XIII 12167, $1-8) .{ }^{43}$ Ludowici plantea incluso la existencia de un asentamiento desconocido de la unidad a orillas del Rin.

La vuelta a Hispania de la legio VII gemina debió de producirse a finales del año 74 d.C., aunque no va a ser hasta el 79 cuando aparezcan las primeras referencias a su estancia en sendas inscripciones de Chaves y Cornoces (Orense) (CIL II 2477 y IRG IV 92, respectivamente). Ahora bien, como hemos visto, su asiento no será ex novo, sino que ocupará el lugar del viejo campamento de la legio VI victrix en León, asentamiento que contaba ya con una larga tradición castrense. No obstante, García y Bellido sostiene que antes de la llegada de la totalidad de la legio VII a la Península, algunas de sus vexillationes pudieron estar ya acantonadas en León construyendo el recinto que más tarde iba a ocupar aquella. Esta opinión se fundamenta en el hallazgo en la ciudad de varias marcas latericias en las que la legión aparece exclusivamente con el epíteto gemina, sin el felix que obtendría en o antes del año 74 d.C. ${ }^{44}$ Aunque el argumento

\footnotetext{
39 A ellas habría que añadir una tercera, muy fragmentada, procedente de la ciudad de León y dada a conocer por GARCÍA y BELLIDO $(1970,324)$.

40 Garzetti 1970, 331-336.

41 Ritterling 1925, col. 1630; García y Bellido 1950, 464.

42 cf. Morillo 2006a, 749-750.

43 Ludowici 1912, 115-116 y 125-127.

44 García y Bellido 1970b, 589 y 591.
} 
cronológico de los epítetos presentes en la producción latericia debe ser descartado, las recientes evidencias arqueológicas no desmienten la presencia militar en León durante este periodo. No existe un paréntesis temporal entre el abandono del campamento de la etapa julioclaudia y el levantamiento de la legio VII, si bien por el momento no puede probarse que dichas tropas pertenecieran a la legión creada por Galba. Sin embargo, nuestra opinión es que los destacamentos habrían llegado con posterioridad al 69/70 d.C., momento en el que la legio VI parte definitivamente de Hispania hacia el Rin. ${ }^{45}$

La reorganización y estabilización de las fuerzas militares a partir del reinado de Vespasiano se plasma en las provincias hispanas en una guarnición estable hasta mediados del siglo III d.C., compuesta por la legio VII gemina asentada en León y varias unidades auxiliares dispersas por el noroeste peninsular.

La obra de García y Bellido constituye el punto de partida de la moderna arqueología romana en León, ${ }^{46}$ cuyos resultados han revelado muchos datos sobre el campamento de la Legión VII Gémina, dotado de un perímetro amurallado con foso y terraplén interior. ${ }^{47}$ Este investigador es el primero que aborda la publicación y análisis de las marcas de la legio VII gemina, proponiendo una datación a partir de la titulatura de dicha unidad reflejada en tejas y ladrillos. Elabora un catálogo de trece variantes de sellos legionarios empleados por la unidad militar, si bien una (legio VII gemina pia felix Severiana Alexandrina) no se constata sobre material latericio. El problema que presenta este trabajo preliminar es que los materiales carecen en su mayoría de contexto arqueológico. Proceden de colecciones antiguas del Museo de León, movimientos de tierras sin control alguno, antiguas obras de restauración en la catedral, etc. Él mismo recupera piezas en las intervenciones que dirige en 1961 y 1967 en la ciudad de León, pero no llega a establecer dataciones estratigráficas para las mismas.

Publicaciones posteriores sobre hallazgos leoneses han ampliado el catálogo de piezas, si bien se conservan muchas más inéditas en el Museo de León. Se han dado a conocer los materiales del Campus de Vegazana, ${ }^{48}$ el monasterio de San Claudio, ${ }^{49}$ el vertedero de Maestro Copín c/v San Salvador del Nido, ${ }^{50}$ el acueducto,${ }^{51}$ el polígono de La Palomera ${ }^{52}$ y el sector de Puerta Obispo..$^{53}$ No obstante, la información arqueológica que proporcionan dichos restos es muy desigual en virtud de su procedencia. Tanto en el Campus de Vegazana como en el monasterio de San Claudio nos encontramos con materiales claramente reutilizados en necrópolis tardorromanas, fuera de su posición original; Maestro Copín y La Palomera son escombreras de época romana; en Puerta Obispo los materiales se recuperaron en paquetes estratigráficos bajoimperiales, muy posteriores a su momento de uso originario como material constructivo. Esto explica que todo el material sellado que conocemos ha aparecido en posición secundaria dentro de las estratigrafías.

45 García Marcos 2002, 182, n. 3.

46 García y Bellido 1970.

47 García Marcos 2002, 181-201; Morillo - García Marcos 2006, 234-240; Morillo 2010, 468-471.

48 Liz Guiral - Amaré 1993.

49 GonzÁlez Fernández 1994.

50 Fernández Freile 2003.

51 Campomanes 2006.

52 Amaré - Álvarez Vega 2006.

53 Morillo - Salido 2013, en prensa. 
La única excepción es el material procedente del acueducto que conducía el agua a la ciudad desde la zona septentrional, que desgraciadamente no tenía asociados materiales cerámicos y numismáticos que permitieran establecer una datación ajustada. El problema que seguimos encontrándonos es que mientras no podamos obtener datos cronoestratigráficos fiables para el material latericio en contextos constructivos altoimperiales indiscutibles, tendremos que seguir remitiéndonos a las dataciones obtenidas a partir de los epítetos militares presentes en los sellos. A través de ellos, constatamos la presencia de marcas desde el gobierno de Vespasiano hasta mediados del siglo III d.C.

Poco a poco vamos conociendo nuevos datos de carácter productivo sobre las figlinae militares legionenses encargadas de la elaboración de material latericio, que analizaremos más adelante.

A continuación presentamos la nómina de los diferentes tipos de estampillas legionarias constatadas en León. A las reseñadas por García y Bellido ${ }^{54}$ y Roldán, ${ }^{55}$ hemos incorporado durante estos años una variante más, $\operatorname{Leg}(\mathrm{io}) \mathrm{VII},{ }^{56}$ que parece ser minoritaria.

\subsubsection{Legio VII}

Se ha constatado esta abreviatura en las intervenciones arqueológicas realizadas en el Campus de Vegazana ${ }^{57}$ y en el polígono de La Palomera. ${ }^{58}$ Debe tratarse de una forma abreviada de la marca legio VII gemina. El sello Legio VII completo y sin abreviaturas e inscrito en un círculo es mencionado por Gómez-Moreno en la villa de Quintana del Marco (León). ${ }^{59}$ Fuera de la Península se verifica su presencia sobre tégulas en el centro alfarero de Rheinzabern (Germania Superior) ${ }^{60}$ y tal vez sobre un ejemplar de Carnuntum, datado en el 68 d.C., ${ }^{61}$ que sería tal vez el primero sellado.

\subsubsection{Legio VII gemina}

La fórmula abreviada legio VII gemina es la más frecuente entre el material latericio encontrado en las intervenciones arqueológicas de León (Fig. 2). El único indicativo cronológico que García y Bellido apunta sobre la aparición de este sello es su posterioridad a octubre del año 69 d.C., fecha de la batalla de Cremona, momento a partir del cual la unidad obtiene el epíteto gemina.$^{62}$ Dicha marca se encuentra perfectamente constatada en la epigrafía. ${ }^{63}$

La abundancia de material latericio con este sello en León, a diferencia del que lleva el apelativo felix, obtenido al parecer en el 73/74 d.C., llevó a García y Bellido

\footnotetext{
54 García y Bellido 1970.

55 ROLDÁN 1974.

56 Liz Guiral - Amaré 1993, 52.

57 Liz Guiral - Amaré 1993, 52.

58 Amaré - Álvarez Vega 2006, 726 y 730.

59 Gómez-Moreno 1925, 67; Liz Guiral - Amaré 1993, 46.

60 Ludowicl 1912, 115-116 y 125-127; Dolata 2001, 133-135.

61 Neumann 1973, 36.

62 García y Bellido 1970, 588.

63 cf. Le Roux 1982; Palao 2006.
} 


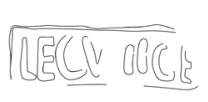

1

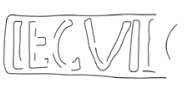

6

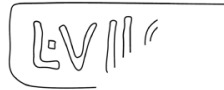

2

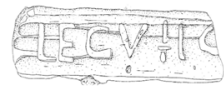

7

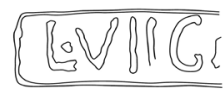

3

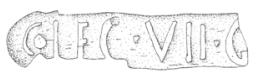

8

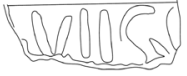

4

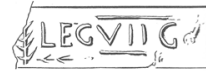

9

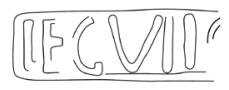

5

LEGUIIGE:

10

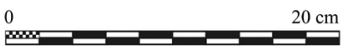

Fig. 2. Marcas Legio VII gemina. Puerta Obispo: $n^{\circ}$ 1-6; La Palomera: $n^{0} 7-8$; procedencia desconocida (Museo de León): nº 9 y 10.

a plantear que antes de esta fecha se habría desarrollado una gran actividad constructiva en el campamento legionario, que atribuye a una vexillatio o destacamento de la legio VII enviado a León antes del desplazamiento del resto de la unidad. ${ }^{64}$ Aunque la presencia de un destacamento en León entre el 69 y el 74 d.C. resulta verosímil por diversos motivos ${ }^{65}$ hoy en día debemos descartar la antecedencia de las marcas con apelativo gemina respecto a las que llevan el felix. En primer lugar, se ha constatado la presencia del título felix en material latericio renano anterior al 73/74 d.C. Por otra parte, en los mismos contextos se constata la convivencia entre los epítetos gemina felix y la aparición del cognomen gemina aislado sobre tejas y ladrillos. ${ }^{66}$

El tipo de material en que aparece es variado, pues la marca aparece sobre ladrillos de tipo bessal y pedal y también sobre imbrices, aunque es mayoritaria sobre tegulae. Aparecen en diversas excavaciones practicadas por García y Bellido, ${ }^{67}$ así como en el Campus de Vegazana ${ }^{68}$ y en Puerta Obispo. ${ }^{69}$ Se documenta también en el centro productivo de Candanedo de Fenar (León). ${ }^{70}$

También esta variante se documenta sobre tégulas de Rheinzabern, coincidiendo con la estancia en la Germania Superior de la VII Gémina entre 70 y 74 d.C., tanto en Rheinzabern como en Maguncia. ${ }^{71}$

\footnotetext{
64 García y Bellido 1970, 589.

65 Morillo 2005, 28.

66 Ludowici 1905, 197-198; ID. 1912, 125-127; PaLAo 2010.

67 García y Bellido 1970, 588.

68 Liz Guiral - Amaré 1993, 52.

69 Morillo - Salido 2013, en prensa.

70 Gutiérrez GonzÁlez 1985, 156-159.

71 Ludowici 1912, 115-116 y 125-127; Dolata 2001, 133-135.
} 


\subsubsection{Legio VII felix}

García y Bellido sólo da a conocer una marca en la que se ha eliminado el primer epíteto (gemina) escribiendo en su lugar la "F" de felix. Según su interpretación, el epíteto de felix fue otorgado a la unidad en el año 73/74 d.C. ${ }^{72}$ Un ejemplar más procede del polígono de La Palomera. ${ }^{73}$ Una tégula con esta misma marca se documenta en Lambaesis (Numidia), coincidiendo con la estancia de la legio VII en dicha provincia. ${ }^{74}$

\subsubsection{Legio VII gemina felix}

Esta marca repite el epíteto nuevo de felix y aparece abreviada como Leg(io) VII Ge(mina) F(elix), o bien como Leg(io) VII G(emina) F(elix) y también como Le(gio) VII G(emina) F(elix). Se ha constatado tanto descontextualizada, ${ }^{75}$ como en todas las intervenciones arqueológicas de León publicadas hasta el momento: Campus de Vegazana; ${ }^{76}$ monasterio de San Claudio, ${ }^{77}$ vertedero de Maestro Copín, ${ }^{78}$ polígono de La Palomera, ${ }^{79}$ acueducto $^{80}$ y Puerta Obispo ${ }^{81}$ (Fig. 3).

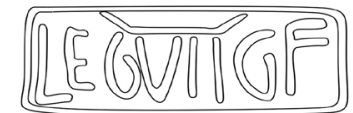

1

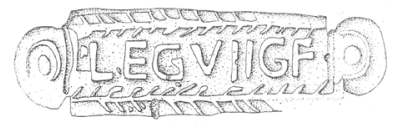

2

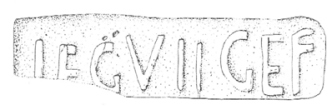

3

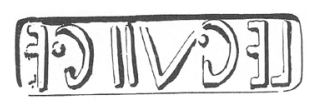

4

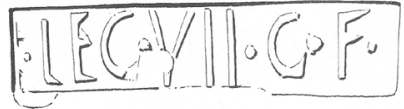

5

$0 \quad 20 \mathrm{~cm}$

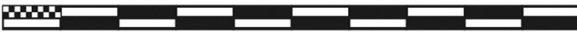

Fig. 3. Marcas Legio VII gemina felix. Puerta Obispo: $\mathrm{n}^{\circ} 1$; La Palomera: $\mathrm{n}^{\circ} 2$ y 3 ; Acueducto: $\mathrm{n}^{\circ} 4$; procedencia desconocida: $\mathrm{n}^{\circ} 5$ (Museo de León) y 6 (MAN).

72 García y Bellido 1970, 591.

73 Amaré - Álvarez Vega 2006, 726 y 730.

74 Roldán 1974, 474, n⿳0 722.

75 García y Bellido 1970, 591-92.

76 Liz Guiral - Amaré 1993, 53.

77 González Fernández 1994, 116.

78 Fernández Freile 2003, 32-42.

79 Amaré - Álvarez Vega 2006, 726 y 730.

80 Campomanes 2006, 443-444.

81 Morillo - SAlido 2013, en prensa. 
La estampilla se localiza asimismo fuera del campamento legionario, tanto en asentamientos militares como Rosinos de Vidriales (Zamora), donde aparecieron sobre cuatro ladrillos bessales,$^{82}$ como en núcleos urbanos. En Italica se documentan dos marcas de este tipo sobre una tégula y un ladrillo, aunque se habla de varias más inéditas. ${ }^{83}$ García y Bellido apunta la excepcionalidad que en uno de ellos no se recoja la abreviatura correspondiente a legio. En la villa de Marialba (León), seguramente trasladada desde su lugar de origen, aparece sobre una tégula. ${ }^{84}$

Se ha constatado sobre tejas (tegulae, imbrices) y ladrillos (sesquipedales y bessales) hallados en uno de los dos hornos latericios de Candanedo de Fenar (León) ${ }^{85}$ así como en la zona de Las Tejas, en Rabanal de Fenar (León). ${ }^{86}$ Se verifica su presencia también sobre varias tégulas halladas en Lambaesi ${ }^{87}$ y probablemente en Porolissum (Dacia). ${ }^{88}$

\subsubsection{Legio VII gemina pia}

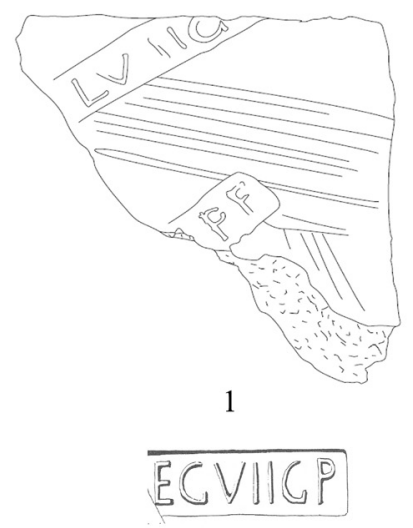

3

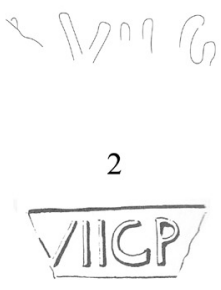

4

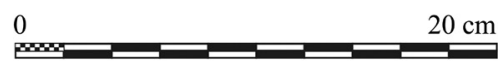

Fig. 4. Marcas Legio VII gemina pia. Puerta Obispo: $\mathrm{n}^{\mathrm{o}} 1$ y 2; procedencia desconocida: $\mathrm{n}^{\mathrm{0}} 3$ y 4 (Museo de León).

El epíteto pia asociado a sellos de la Legión VII no se emplea hasta época de Septimio Severo. Su concesión se asocia al apoyo de la legio VII en el conflicto que en-

82 Martín Valls et alii 2002, $\mathrm{n}^{\circ} 18-21$.

83 CIL II 1125; CIL II 6252, 2; CILA 3, 580; García y Bellido 1970, 592, fig. 52, 22; ID. 1979, 22, nota 36, fig. 12.

84 Gómez-Moreno 1925, 82; Liz Guiral - Amaré 1993, 46.

85 GutiérRez GonZÁlez 1985, 156-159.

86 GonzÁlez García - Pérez Seoane 1989, 74, lám. I.

87 RoldÁn 1974, 474, nº 722.

88 Gudea 1978, 65-75; Le Roux 1981, 119-200; Abascal 1986, 319-322. 
frentó al emperador con Clodio Albino en el año 195 d.C. Dicho cognomen aparece por primera vez entre el 208 y 211 d.C. (CIL II 4121), en una inscripción tarraconense de Q. Hedius Lollianus ${ }^{89}$ Es curioso que ya en esta inscripción se antepone el nuevo cognomen pia al epíteto felix, anomalía cronológica que se mantendrá en otras variantes de sellos. Se han recuperado varias estampillas con la abreviatura L(egio) VII $G($ emina $) P(i a)$ en materiales de León, descontextualizadas, ${ }^{90} \mathrm{y}$ en las intervenciones del polígono de La Palomera ${ }^{91}$ y Puerta Obispo ${ }^{92}$ (Fig. 4).

\subsubsection{Legio VII gemina pia felix}

En la ciudad de León se han hallado restos de material latericio en que el epíteto pia aparece con el de gemina antepuesto y seguido del de felix. Se documentan en todos los contextos arqueológicos publicados ${ }^{93}$ (Fig. 5). En todos los casos la abreviatura es L(egio) VII G(emina) P(ia) F(elix).

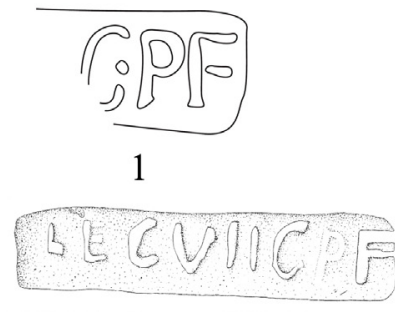

3

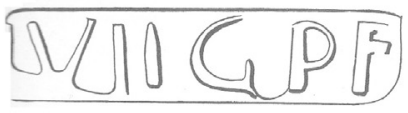

5

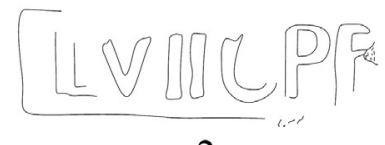

2

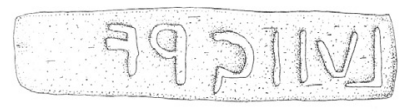

4

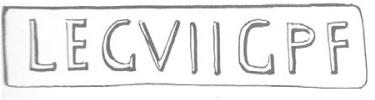

6

0 $20 \mathrm{~cm}$

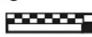

Fig. 5. Marcas Legio VII gemina pia felix. Puerta Obispo: $\mathrm{n}^{\mathrm{o}} 1$ y 2 ; La Palomera: $\mathrm{n}^{\mathrm{0}} 3$ y 4 ; procedencia desconocida: $n^{\circ} 5$ y 6 (Museo de León).

89 García y Bellido 1970, 593.

90 García y Bellido 1970, 593.

91 Amaré - Álvarez Vega 2006, 726 y 730.

92 Morillo - SAlido 2013, en prensa.

93 García y Bellido 1970, 593-94; Liz Guiral - Amaré 1993, 54; González Fernández 1994, 116; Amaré - Álvarez Vega 2006, 726 y 730; Morillo - Salido 2013, en prensa. 


\subsubsection{Legio VII gemina Antoniniana pia felix}

A partir del gobierno del emperador Caracalla, la legio VII gemina recibe el apelativo de Antoniniana. En este momento se inicia la costumbre de asignar epítetos personales de los emperadores a las unidades militares. ${ }^{94}$ Esta designación la hallamos también en lápidas. ${ }^{95}$ En todos los sellos la "F" de felix va detrás de la "P", abreviatura de pia. El cognomen Antoniniana, que se abrevia indistintamente como " $\mathrm{A}$ " y a veces en "AN", se ha documentado en varias intervenciones arqueológicas realizadas en León. En este caso aparece en las excavaciones en el Huerto de San Isidoro, ${ }^{66}$ el Campus de Vegazana, ${ }^{97}$ el monasterio de San Claudio, ${ }^{98}$ La Palomera ${ }^{99}$ y Puerta Obispo ${ }^{100}$ (Fig. 6). A poca distancia de León, concretamente entre Marialba y Lancia, en Valdesogo de Arriba y Valdesogo de Abajo, se encontraron varias tégulas con esta variante. ${ }^{101}$

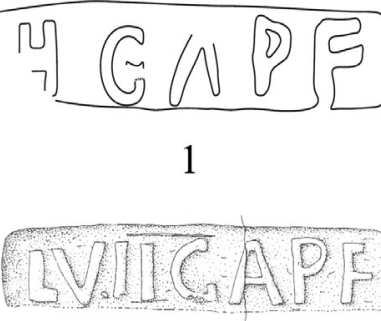

3

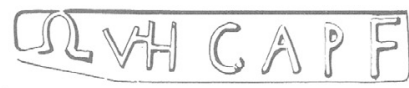

5

0

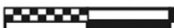

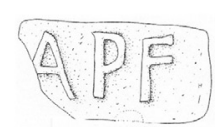

2

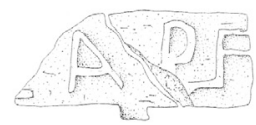

4

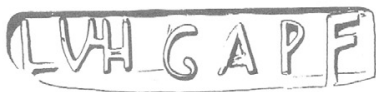

6

Fig. 6. Marcas Legio VII gemina Antoniniana pia felix. Puerta Obispo: $n^{\circ} 1$; La Palomera: ${ }^{\circ}$ 2-4; procedencia desconocida: $\mathrm{n}^{\circ} 5$ y 6 (Museo de León).

\footnotetext{
94 FITZ 1983.

95 García y Bellido 1970, 594.

96 García y Bellido 1970, 594.

97 Liz Guiral - Amaré 1993, 54.

98 GonzÁlez Fernández 1994, 116.

99 Amaré - Álvarez Vega 2006, 726 y 730.

100 Morillo - SAlido 2013, en prensa.

101 Loewinsohn 1991, 197, nota 6; Liz Guiral - Amaré 1993, 46.
} 


\subsubsection{Legio VII gemina Maximiniana pia felix}

La marca, abreviada como L(egio) VII g(emina) Max(iminiana) p(ia) f(elix), es minoritaria en el conjunto de material latericio, aunque se ha constatado durante las intervenciones arqueológicas desarrolladas en León ${ }^{102}$ (Fig. 7).

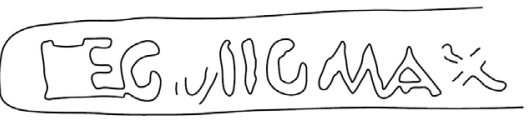

1

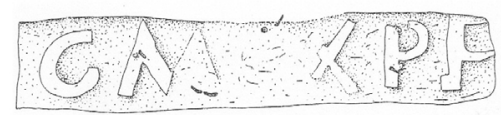

2

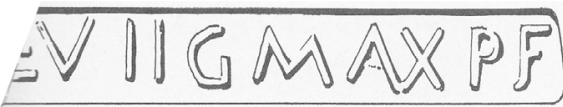

3

0 $20 \mathrm{~cm}$

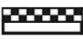

Fig. 7. Marcas Legio VII gemina Maximiniana pia felix. Puerta Obispo: $\mathrm{n}^{\circ} 1$; La Palomera: $\mathrm{n}^{\circ} 2$; procedencia desconocida: $\mathrm{n}^{\mathrm{o}} 3$ (Museo de León).

\subsubsection{Legio VII gemina Gordiana pia felix}

Esta marca ha de datarse entre el 238 y 244 d.C., fechas del reinado de Gordiano III. Son relativamente numerosos los sellos con tal leyenda. La abreviatura es muy semejante a la de los sellos anteriores, con el cognomen Gordiana delante de $p$ (ia) f(elix). Como rasgo epigráfico diferenciado debemos mencionar la presencia de interpunciones. La abundancia de esta marca se ha señalado en diversas publicaciones. Así se constata en el Huerto de San Isidoro, ${ }^{103}$ Monasterio de San Claudio, ${ }^{104}$ La Palomera ${ }^{105}$ y Puerta Obispo ${ }^{106}$ (Fig. 8), además de un ejemplar de Italica sobre tegula en el que también parece faltar la abreviatura $L$ (egio). ${ }^{107}$

102 García y Bellido 1970, 595; Amaré - Álvarez Vega 2006, 726 y 730; Morillo - Salido 2013, en prensa.

103 García y Bellido 1970, 595.

104 GonzÁlez Fernández 1994, 116.

105 Amaré - Álvarez Vega 2006, 726 y 730.

106 Morillo - Salido 2013, en prensa.

107 García y Bellido 1970, 592, nº 22, fig. 58, 7. 


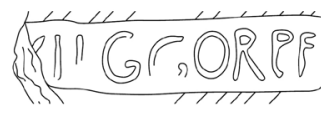

1

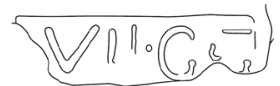

5

0

300

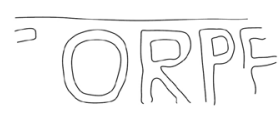

2

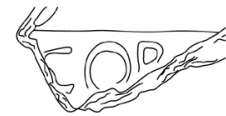

3

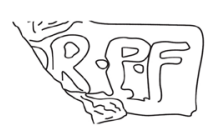

4

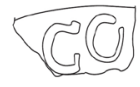

6

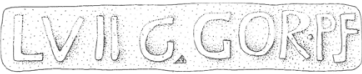

7

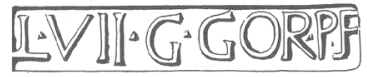

8

Fig. 8. Marcas Legio VII gemina Gordiana pia felix. Puerta Obispo: $\mathrm{n}^{\circ} 1-6$; La Palomera: ${ }^{\circ}$ 7; procedencia desconocida: $\mathrm{n}^{\circ} 8$ (Museo de León).

\subsubsection{Legio VII gemina Philippiana pia felix}

Las estampillas con la abreviatura L(egio) VII G(emina) Phil(ippiana) P(ia) F(elix), datadas entre el 244 y el 249 d.C., se conocen sobre ladrillos y tégulas de varias intervenciones $^{108}$ (Fig. 9). Gómez-Moreno menciona la aparición de esta variante en el monasterio leonés de San Miguel de la Escalada. ${ }^{109}$

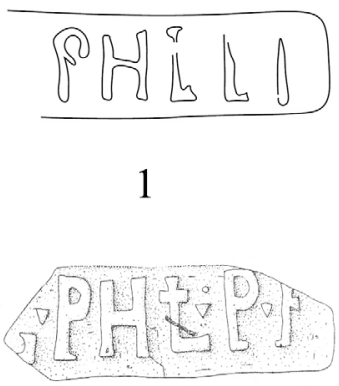

3

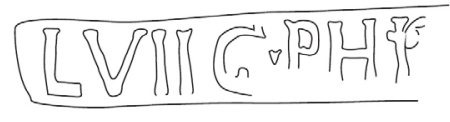

2

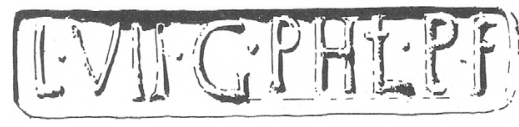

4

0

$20 \mathrm{~cm}$

Fig. 9. Marcas Legio VII gemina Philippiana pia felix. Puerta Obispo: $n^{\circ} 1$ y 2; La Palomera: $n^{\circ} 3$; procedencia desconocida: $n^{\circ} 4$ (Museo de León).

108 García y Bellido 1970, 596; Liz Guiral - Amaré 1993, 55; Amaré - Álvarez Vega 2006, 726 y 730 ; Morillo - SALido 2013, en prensa.

109 Gómez-Moreno 1925, 55; Liz Guiral - Amaré 1993, 46; EE IX, 422b. 


\subsubsection{Legio VII gemina Deciana Traiana}

La marca, abreviada como L(egio) VII G(emina) F(elix) D(eciana) T(raiana), data del gobierno de Traiano Decio, entre los años 249 y 251 d.C. García y Bellido advierte sobre la existencia de un único testimonio en ladrillo sin procedencia custodiado en el Museo de León, ${ }^{110}$ aunque se ha hallado otra pieza en la vecina villa de Navatejera ${ }^{111}$ (Fig. 10).
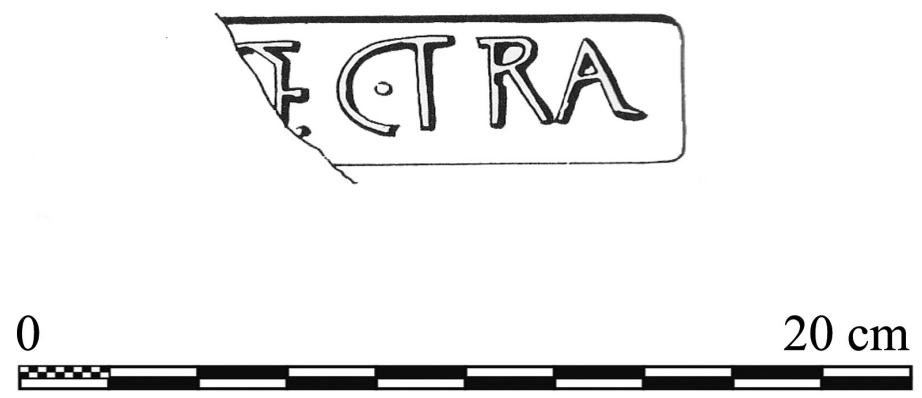

Fig. 10. Marca de la Legio VII gemina Felix Deciana Traiana, según García y Bellido (1970, fig. 60).

\subsubsection{2. ¿Legio VII Claudiana?}

Solamente se halló una marca retrógrada que García y Bellido atribuye al emperador Claudio II Gótico, que gobernó en los años 269 y 270 d.C., que aparece sin contexto ${ }^{112}$ (Fig. 11, $\mathbf{n}^{\mathbf{0}}$ 7).

\subsubsection{3. ¿Legio VII gemina Quintilliana?}

García y Bellido ${ }^{113}$ señala la existencia de dos ladrillos aparecidos en el Huerto de San Isidoro, con la abreviatura $\operatorname{Leg}($ io) VII Ge(mina) Qui(ntilliana), que atribuye a Quintilo, hermano de Claudio Gótico, por tanto, se fecharía en el año 270 d.C. Tanto esta variante como la anterior plantean numerosos problemas de lectura (Fig. 11, $\mathbf{n}^{\mathbf{0}}$ 8 y 9 ).

Las marcas de la Legión VII, muy abundantes, se documentan sobre material constructivo latericio de todo tipo: tegulae, imbrices, bipedales, pedales, bessales. Una simple aproximación permite identificar once variantes confirmadas de marcas, correspondientes a casi un centenar de punzones distintos. Las estampillas más abun-

110 García y Bellido 1970, 596-97.

111 Gómez-Moreno 1925, 65; Liz Guiral - Amaré 1993, 46.

112 García y Bellido 1970, 597.

113 García y Bellido 1970, 597. 


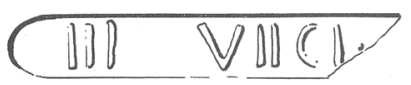

1

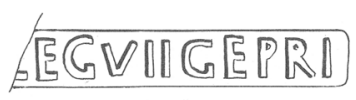

4

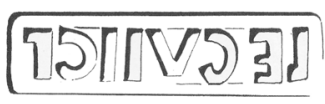

7

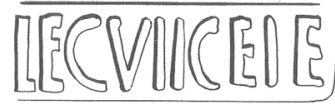

2

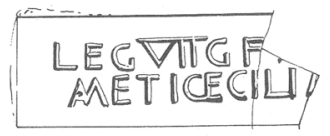

5

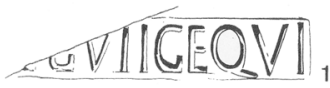

8

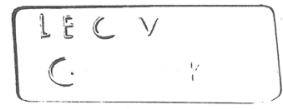

3

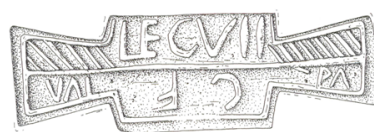

6

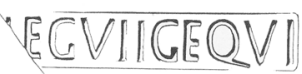

9

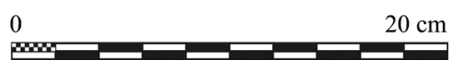

Fig. 11. Sellos militares con abreviaturas de nombres personales, entre las que incluimos las marcas que García y Bellido interpreta como apelativos legionarios: Claudiana $\left(\mathrm{n}^{\circ} 7\right)$ y Quintiliana ( $\mathrm{n}^{\circ} 8$ y 9$)$.

dantes son tanto la Legio VII gemina como la Legio VII gemina felix que, sin duda, deben corresponder entre la llegada de la unidad a León hasta el ascenso al trono de Septimio Severo. Sin embargo, resulta muy llamativa la abundancia de sellos de algunos emperadores del siglo III d.C. El caso más llamativo es el de las estampillas de Gordiano III (238 y 244 d.C.) y de Filipo I y II (244 y el 249 d.C.). Teniendo en cuenta que se encuentran sobre material latericio constructivo, tal vez la abundancia de estas marcas nos informa sobre reformas considerables en algunos edificios del campamento. A partir de los datos estratigráficos, ya hemos constatado importantes transformaciones en las termas legionarias en contextos temporales coincidentes. ${ }^{114}$

Una de las cuestiones más problemáticas es el del momento final del sellado en el campamento de León. Según García y Bellido, se documenta una posible estampilla de Claudio II Gótico (269-270 d.C.), que se formula Le(gio) VII Cl(audiana), y dos de Quintilo (270 d.C.), con la abreviatura Leg(io) VII Ge(mina) Qui(ntilliana). ${ }^{115}$ Sorprende, por una parte, la parquedad del registro de ambos emperadores; por otra, el hecho de que las últimas producciones latericias en cantidad considerable finalicen hacia el 250 d.C., existiendo un lapso temporal considerable, de casi 20 años, hasta el

114 Morillo - Salido 2013, en prensa.

115 García y Bellido 1970, 597. 
269 d.C., momento de asunción del poder por parte de Claudio II. Parece más lógico pensar que García y Bellido interpretó como marcas de Claudio II y Quintilo lo que en realidad corresponde a nombres de trabajadores de las oficinae latericias militares, de los que ya conocemos varios. ${ }^{116} \mathrm{Si}$ aceptamos esta hipótesis como la más verosímil, deberíamos descartar las dos últimas variantes señaladas por García y Bellido. La última fase de las tegularias de la Legión VII terminaría en los años centrales del siglo III d.C., momento en que la profunda crisis económica, política y militar tuvo que provocar importantes repercusiones en el campamento de León.

\subsection{Ala Parthorum}

Entre las unidades auxiliares de infantería y caballería atestiguadas por las fuentes epigráficas, las recientes intervenciones arqueológicas desarrolladas en Herrera de Pisuerga han permitido añadir un nuevo cuerpo de caballería, cuya presencia en la Península era completamente desconocida, el ala Parthorum. Este cuerpo, adscrito posiblemente a la legio VI victrix, se establece en época de Nerón en un nuevo recinto ubicado sobre el ya abandonado campamento de la legio IV Macedonica en Herrera de Pisuerga. ${ }^{117}$ Tal vez esta unidad sea una de las dos alas de caballería de nombre desconocido mencionadas junto con la Legión VI y tres cohortes de infantería en la nómina de tropas que se levanta con Galba contra Nerón (Suetonio, De Vita Duodecim Caesarum, Galba X, 2).

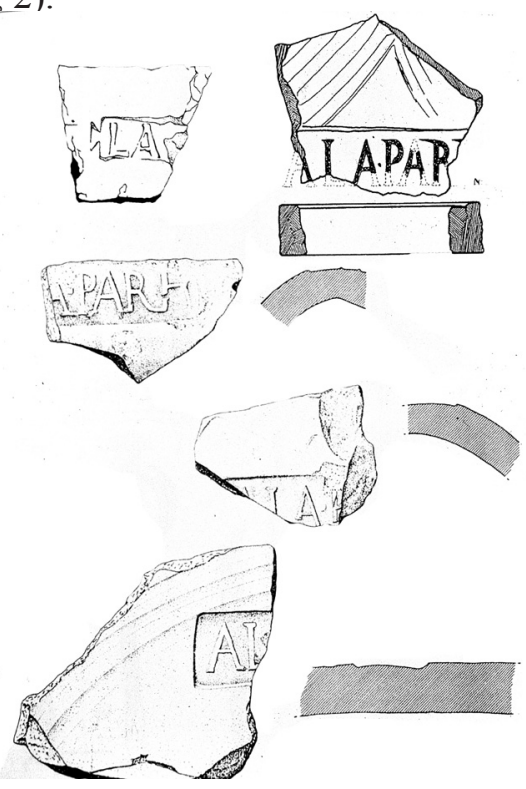

Fig. 12. Tegulae e imbrices del ala Parthorum (Herrera de Pisuerga). Imág.: Pérez González 1996, fig. 2.

116 Liz Guiral - Amaré 1993, 56; Le Roux 1999, 118; Campomanes 2006, 452.

117 Morillo 2000; Morillo et alii 2006, 315-319. 
Se conocen fuera de la Península dos alas con el étnico Parthorum: el ala I Augusta Parthorum, ampliamente documentada en Mauretania Caesariense a partir del 107 d.C., y el ala Parthorum Veterana, que aparece citada solamente sobre un anillo de plata procedente de la Germania Inferior. ${ }^{118}$ Aunque no podemos establecer con precisión el recorrido del ala antes de su llegada a Hispania, no cabe duda de que la unidad documentada en Herrera de Pisuerga es la misma que marcha a comienzos del siglo II d.C. al norte de África, donde aparece en un primer momento con el simple apelativo de ala Parthorum hasta adquirir el título de Augusta. ${ }^{119}$

En este caso en particular, la identificación del cuerpo militar ha venido propiciada por la existencia de marcas militares sobre material latericio que recogen su nombre, siempre con la misma fórmula epigráfica: Ala Parth(orum). Se conocen tan sólo cinco ejemplares, tres tégulas y dos ímbrices, dados a conocer hace algunos años ${ }^{120}$ (Fig. 12). A juzgar por el registro arqueológico, el asentamiento del ala Parthorum en su fuerte en Herrera de Pisuerga debió tener lugar en época neroniana e incluso flavia. ${ }^{121}$ No se conocen datos relativos a la planta y el sistema constructivo del campamento.

\subsection{Cohors I Celtiberorum}

Antes de su establecimiento en el fuerte de Cidadela (A Coruña), se localiza esta cohors en Mauritania, donde en el 109 d.C. se le otorga la ciudadanía romana como recompensa a sus méritos militares. ${ }^{122} \mathrm{La}$ unidad permanece en el fuerte de Cidadela hasta finales del siglo III d.C. ${ }^{123}$ Durante todo el siglo II d.C. diversos testimonios epigráficos confirman su actuación en todo el cuadrante noroeste peninsular, concentrándose tanto en el interior como en el exterior de su campamento. ${ }^{124}$

El campamento presenta muralla de piedra y foso, que encierran una superficie de unas 2,4 ha. La identificación de la unidad aquí acantonada ha sido posible dada la recuperación, dentro del propio yacimiento, de casi quinientas tégulas con tan sólo tres ladrillos en los que figuraban marcas legionarias. ${ }^{125}$ Las modalidades de estos sellos y sus grafías varían, aunque predominan los sellos rectangulares en relieve con las esquinas redondeadas que presentan cuatro variantes: $C$ (ohors) $P($ rima) C(eltiberorum), Coh(ors) I C(eltiberorum), C(ohors) I C(eltiberorum) y C(o)ho(rs) I C(eltiberorum). ${ }^{126}$ Se han constatado 18 punzones diferentes ${ }^{127}$ (Fig. 13).

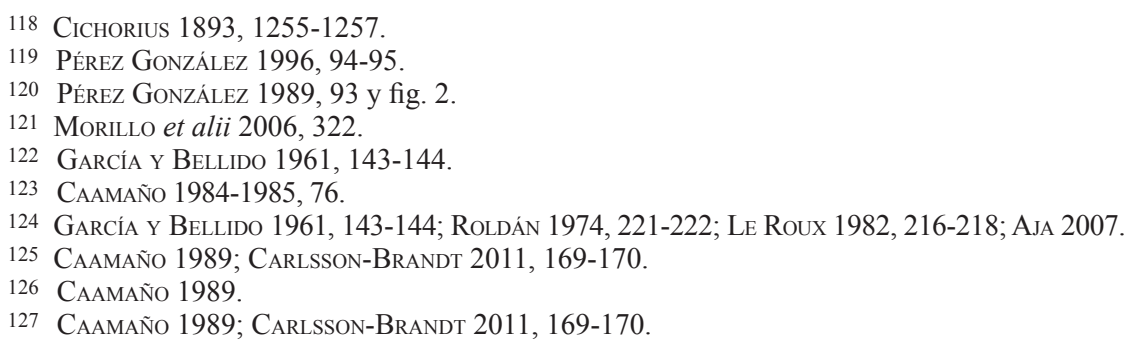



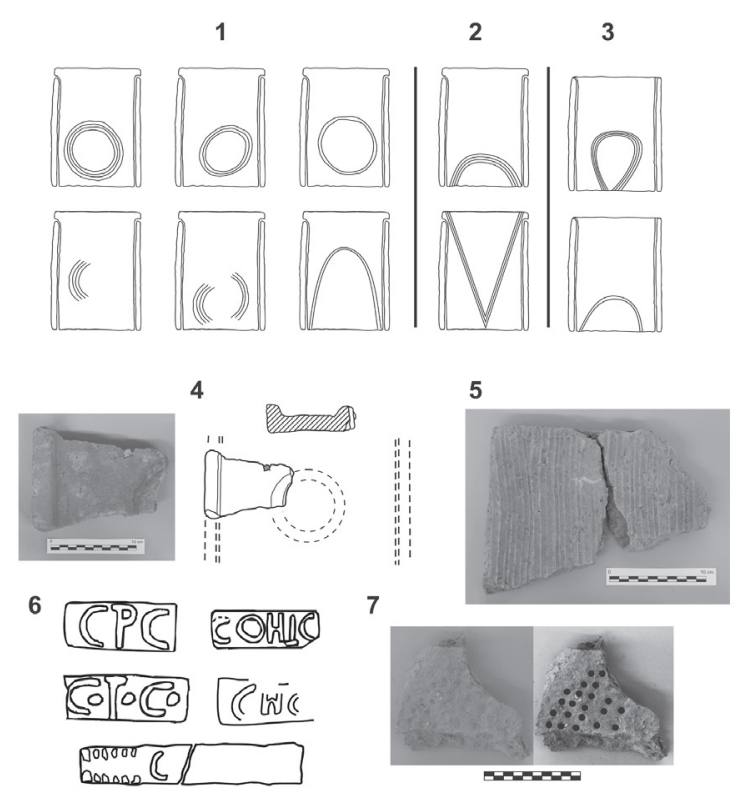

8
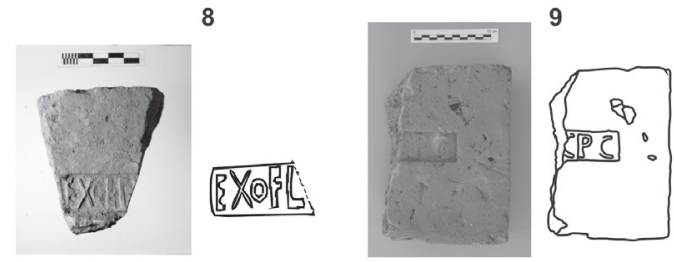

Fig. 13. Sellos militares sobre material latericio del campamento de la Cohors I Celtiberorum de Cidadela (A Coruña). Imág.: Carlsson-Brandt Fontán 2011, 177.

Entre los materiales recuperados en el fuerte se constata una marca Ex of $L[\ldots]$ sobre una tégula, que no podemos vincular con la oficina militar. ${ }^{128}$

A partir del análisis de los materiales recogidos en el campamento, así como de la información proporcionada por las fuentes epigráficas, se sabe que el establecimiento de la cohorte en Cidadela se produce a principios del siglo II d.C., permaneciendo aquí hasta algún momento del siglo IV d.C. Este constituye el único indicativo sobre la cronología de las marcas latericias, ya que no se ha dado a conocer ninguna referencia sobre su posición dentro de las estratigrafías.

\subsection{Ala II Flavia}

Conocemos pocos datos relacionados con el origen de esta unidad, así como acerca del momento de establecimiento en el fuerte de Rosinos de Vidriales, que se erige en

128 CARLsSon-Brandt 2011, 170. 
piedra sobre el antiguo campamento legionario de la legio X gemina, ocupando una superficie de 4,7 ha. Se suele aceptar que el acantonamiento tuvo lugar a finales del siglo I o comienzos del II d.C., permaneciendo hasta los siglos III o IV. ${ }^{129}$

Se conocen tan sólo dos ejemplares de marca sobre material latericio procedentes del recinto militar de Rosinos de Vidriales que se han asociado al ala II Flavia (Fig. 14). Ambas, en relieve sobre tegulae, presentan el desarrollo Al(a) F(lavia) en cartela rectangular y proceden del mismo punzón. ${ }^{130}$ Una tercera parece elaborada a mano alzada. Respecto a su cronología, se apunta su relación con la construcción de la porta praetoria del campamento auxiliar, datada por tipología entre finales del siglo I y comienzos del II d.C. ${ }^{131}$

La unidad de caballería se sirvió de tejas civiles, entre las que destacan las de $G$. Coelus, de las que se conservan más de un centenar. ${ }^{132}$
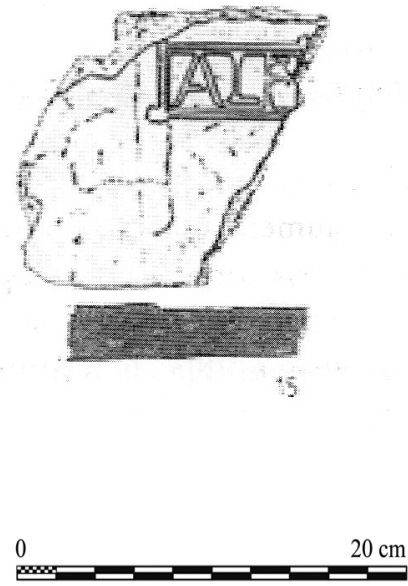

$\mathrm{cm}$

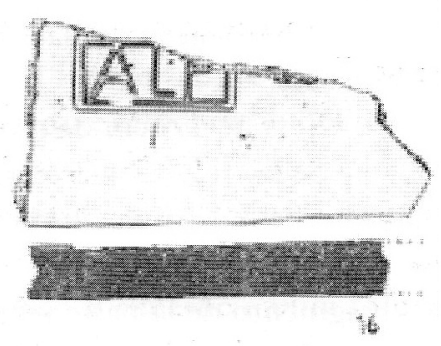

Fig. 14. Tejas militares procedentes de Rosinos de Vidriales con marca del Ala II Flavia. Imág.: Martín Vals - Romero - Carretero 2002, fig. 1 (con modificaciones).

\subsection{Marcas indeterminadas}

Dentro de este epígrafe hemos agrupado varias marcas publicadas como militares, pero que plantean todavía dudas sobre su identificación. Algunas de ellas proceden de asentamientos de carácter militar mientras otras, que lógicamente ofrecen más discusión, provienen de asentamientos civiles o indeterminados.

Entre los campamentos que proporcionan marcas que se han considerado militares

\footnotetext{
129 CARretero - Romero CARnicero 1996; CARretero 2006, 178-193.

130 Martin Valls et alii 2002, 141 y 152-153, fig. 3.15 y 3.16.

131 Martin Valls et alii 2002, 152; CARretero 2006, 181-183.

132 Martin Valls et alii 2002, 152.
} 
se encuentran Herrera de Pisuerga y Baños de Bande. En Herrera de Pisuerga se han dado a conocer en diversos lugares del yacimiento varias marcas sobre cerámica común y material latericio en las que puede leerse $\mathrm{CH}$ y $\mathrm{COH} .{ }^{133} \mathrm{La}$ marca $\mathrm{CO}_{\zeta} \mathrm{H}$ ? aparece asimismo sobre la base de una lucerna de canal de la forma Loeschcke IX que publicamos hace algunos años, donde ya sugeríamos su probable fabricación local. ${ }^{134}$

Las excavaciones desarrolladas en este mismo yacimiento han proporcionado diversos testimonios que podemos relacionar asimismo con la cohors I Gallica. ${ }^{135}$ El testimonio aparentemente más antiguo de esta unidad en la Península parece ser precisamente la lápida hallada hace unos años en Herrera de Pisuerga, en la que se menciona a Cornelianus, praefectus c(ohortis) P(rima) G(allica) e(quitata) c(ivium) $r$ (omanorum), datada por García y Bellido a comienzos del siglo II d.C. ${ }^{136}$ En la zona occidental del actual casco urbano se documentan numerosos materiales entre los que se hallan restos de ajuar metálico correspondientes a una unidad de caballería. Entre ellos se encuentra un aplique decorativo que debemos interpretar como una placa de atalaje equino, un pequeño disco metálico recortado que presenta en su anverso la inscripción S Victorini Firm(i) C(ohors) I, esto es, "de S. Victorino "el fuerte", de la I Cohorte". ${ }^{137}$ Los materiales cerámicos y numismáticos permiten establecer la cronología del acantonamiento entre el 60 y 100 d.C. ${ }^{138}$

Baños de Bande, fuerte auxiliar del periodo altoimperial, de unas 3 ha y dotado de muralla pétrea y foso de perfil en "V", ${ }^{139}$ ha proporcionado por el momento escasos testimonios relativos a tejas y ladrillos militares. Las excavaciones arqueológicas desarrolladas en el mismo han revelado que la mayor parte del abastecimiento de material constructivo latericio era cubierto mediante producciones civiles. Se constatan tejas y ladrillos con marcas de alfareros como Cloutus, Rufus, Marcius y Saturninus. ${ }^{140}$ Sin embargo, se conservan tres tégulas que se han interpretado como militares. Los investigadores responsables han propuesto la lectura de una de ellas como legio VII gemina ${ }^{141}$ hipótesis poco verosímil, puesto que además de que su lectura es compleja, no existe paralelo alguno para dicha marca entre las producciones leonesas. Las dos marcas restantes, que se conservan incompletas, se han interpretado como pertenecientes a una cohors III, que se ha propuesto como ocupante del campamento. ${ }^{142}$ Pero si bien en una de ellas, rectangular y con los signos en relieve, se lee C(ohors)? III [...], la otra, incisa, resulta mucho menos clara.

Otra de las supuestas marcas militares proviene de un yacimiento cuya definición aún se encuentra pendiente. Nos referimos a Rebolledo-Camesa (Valdeolea), situado cerca del límite meridional de la actual Cantabria y junto a la principal vía de pene-

\footnotetext{
133 Illarregui 1999, 183; Pérez GonZÁlez - Illarregui 2006, 120.

134 Morillo 1999, 133-134 y 291, nº 28.

135 Morillo et alii 2006, 322-323.

136 García y Bellido 1959, 12.

137 Morillo - Fernández IBÁÑEz 2001-2002.

138 Morillo 1999, 40.

139 Rodríguez Colmenero - Ferrer Sierra 2006.

140 Rodríguez Colmenero - Ferrer Sierra 2006, 163-174.

141 Rodríguez Colmenero - Ferrer Sierra 2006, 629, fig. 1.

142 Rodríguez Colmenero - Ferrer Sierra 2006, 630-631, fig. 2 y 3.
} 
tración desde la Meseta hacia el interior del territorio cántabro. Las intervenciones realizadas a comienzos de los años ochenta en la zona de El Conventón dieron a conocer un edificio romano -probablemente termal- datado entre los siglos I y III d.C., que los investigadores consideraban asociado a una villa, reocupado en época visigoda y más tarde por una necrópolis altomedieval. ${ }^{143}$ Recientemente se ha propuesto un carácter militar para otro asentamiento constatado en la zona de La Cueva. ${ }^{144}$ Los argumentos se han elaborado a partir de la reinterpretación de las estructuras constructivas, que adoptan una forma rectangular que recuerda a un barracón de tropa, y al hallazgo de un fragmento de material latericio con una marca en relieve interpretada como $(L) E G$, que se ha asociado con la legio IIII Macedonica, muy presente en la región a través de los hitos augustales. ${ }^{145}$ Dicha lectura resulta muy poco verosímil, tal y como demuestra el hallazgo en el yacimiento de varias tégulas más con marca $C A E C$ (ilius), estampilla que se ha identificado de forma errónea con la marca militar $L E G^{146}$ (Fig. 15a).
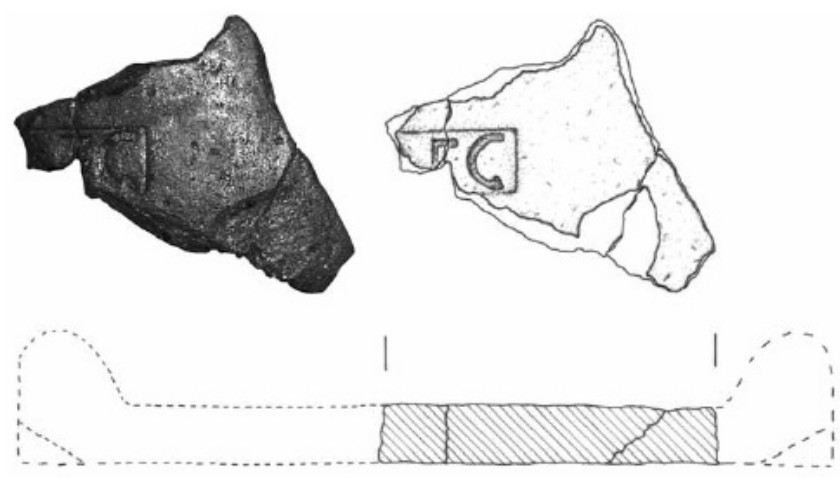

a
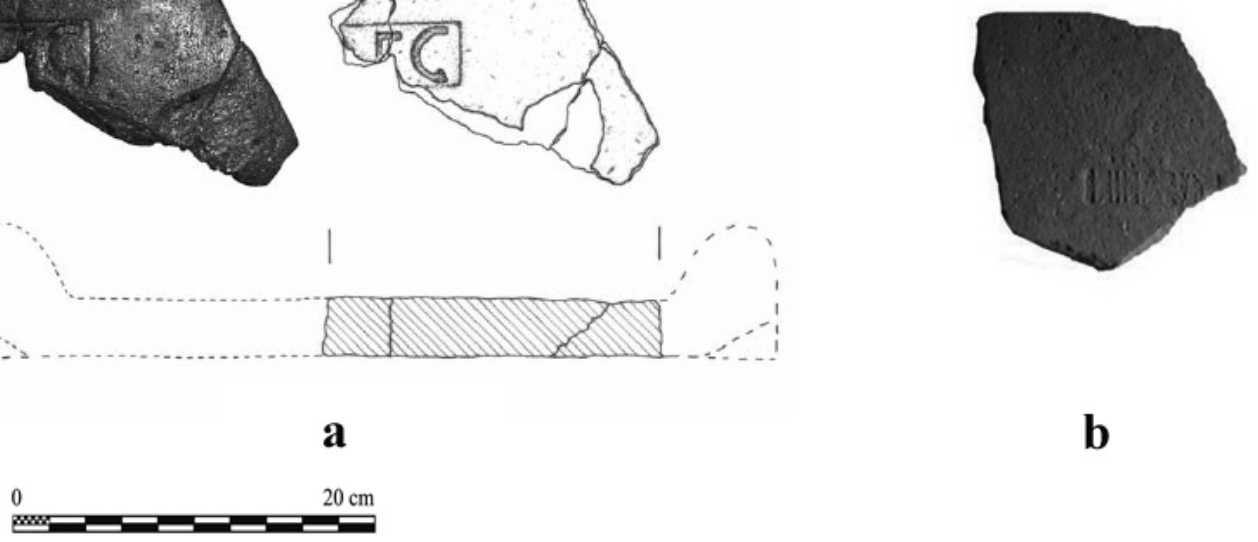

Fig. 15. Marcas erróneamente interpretadas como sellos militares: a- Tegula procedente de Rebolledo-Camesa; b- Marca de Quinta da Urgueira (Manigoto, Pinhel, Portugal). Imág.: Fernández Vega 2010, 7, fig. 1 y 2; Perestrelo 1998; ID. 2008, 60-61, fig. 8.

La mayor parte de los investigadores descarta la presencia en este lugar de un destacamento militar, ${ }^{147}$ planteando otras posibilidades como la identificación de este asentamiento como una aglomeración secundaria ${ }^{148} \mathrm{e}$ incluso con la propia Iuliobriga ${ }^{149}$

\footnotetext{
143 García Guinea et alii 1985; VAn den Eynde 1999.

144 Illarregui 1998.

145 RoBles 1997.

146 Fernández Vega 2010, 7 y 28, figs. 1, 2 y 8.

147 Robles 1997; Aja 2001; Morillo 2008, 155.

148 Fernández OchoA - Gil Sendino 2008, 464.

149 Fernández Vega et alii 2005; Fernández Vega 2010.
} 
Recientemente se han dado a conocer varias marcas sobre tégulas procedentes de la ciudad romana de Clunia. Sólo una de las estampillas está completa, mientras las otras dos han llegado parcialmente, habiéndose perdido precisamente la parte correspondiente a la unidad militar. Son sellos de forma semicircular con las letras en relieve, en las que se ha leído L(egio) IIII Ma (cedonica) Ra [(...? fecit], con nexos entre "M" y "A" y entre "R" y "A" 150 (Fig. 16). Las medidas oscilan entre 3,5-4 cm de radio y las letras presentan una altura de $2,4 \mathrm{~cm}$. El último grupo de letras, "RA" se asocia tal vez con trabajadores relacionados con el proceso productivo, pero se apuntan otras posibilidades, como el propio nombre del legado, tal y como conocemos en otros lugares. ${ }^{151}$ Recientemente se ha replanteado el grupo final de letras, que debe ser reinterpretado como $R U F(u s)$ con varias ligaduras (AE 2008 697a-c; HEp $17,2008,33 a-c)$.
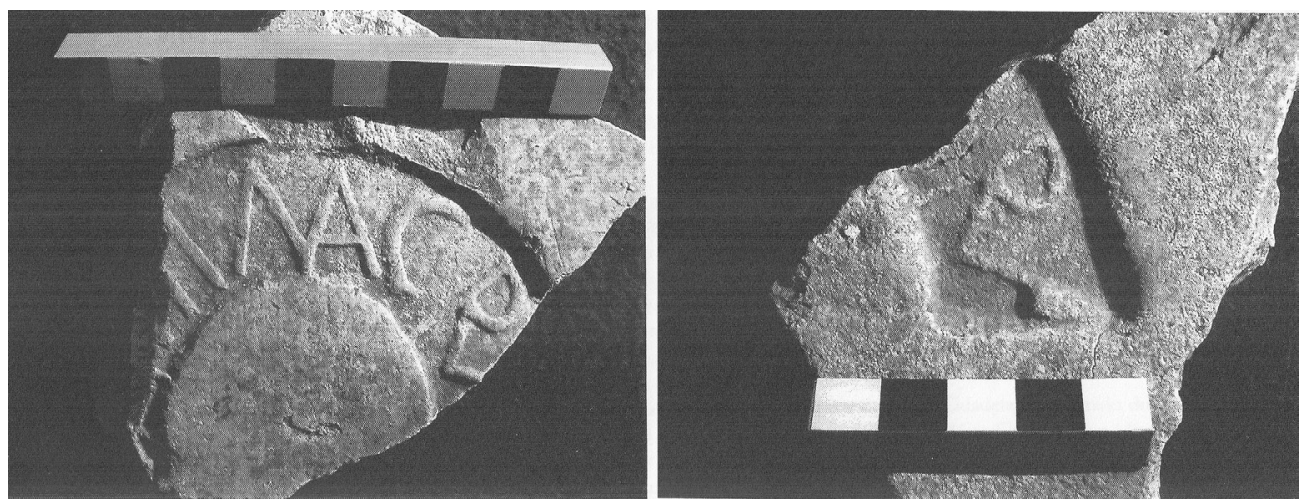

Fig. 16. Sellos sobre material latericio de la Legio IIII Macedonica en Clunia. Imág.: Irujo 2008, láms. 2 y 3.

Sin embargo, las diferentes publicaciones coinciden en aceptar la identificación del primer grupo de letras con la marca de la legio IIII Macedonica, considerando estos sellos como un argumento sobre la presencia de una vexillatio de la legio IIII Macedonica en Clunia, posiblemente encargada de la construcción de infraestructuras y edificios en la capital del conventus al que estaba adscrita la unidad militar, asentada como sabemos en el campamento de Herrera de Pisuerga entre el 19 a.C. y el 39 d.C. ${ }^{152}$

Si bien la presencia de dicha vexillatio en Clunia debe ser considerada con cierta cautela debido a la ausencia de otras evidencias arqueológicas, no cabe duda de que la lectura de las marcas presenta similitudes muy llamativas con la nomenclatura de la legión constatada en la epigrafía disponible tanto dentro como fuera de su campa-

150 IRUJO 2008.

151 IRUJO 2008.

152 MoriLlo et alii 2006, 315-319. 
mento. ${ }^{153}$ Sin embargo no se conoce sello militar alguno de la IIII Macedónica hasta después de su salida de la provincia Tarraconense en dirección a Germania Superior. Los abundantes registros estratigráficos de Herrera de Pisuerga no han revelado ningún material latericio sellado. Por otra parte, la propia forma de la estampilla es un criterio que corrobora su antigüedad. Steinby señala que las marcas semicirculares aparecen en Roma en la década de los 30 del siglo I d.C., continuando en uso hasta el reinado de Nerón ${ }^{154}$ y se verifica su presencia sobre el material latericio militar más antiguo, entre el que se encuentran producciones de la Legión IIII Macedónica. De cualquier forma sería la marca más temprana en la Península, cuya presencia en Clunia, vinculada a una legión que no firma sus producciones en Hispania, es una cuestión que no puede resolverse fácilmente.

Otra posible marca de la legio IIII Macedonica se ha dado a conocer sobre un fragmento de tégula procedente de la Quinta da Urgueira (Manigoto, Pinhel, Portugal). En este caso la marca aparece en una cartela rectangular de 11,5 x 2,7 cm (Fig. 15b). Se ha publicado como L(egio) IIII Ma (cedonica) o M(ace)d(onica). ${ }^{155}$ Sin embargo, interpretaciones epigráficas posteriores descartan esta lectura (AE 1988 705; HEp 8, 1998, 604).

\section{El origen del sellado militar en Hispania}

Una de las cuestiones que mayor interés ha despertado entre los investigadores durante los últimos años ha sido el origen de las estampillas militares, ${ }^{156}$ aspecto directamente relacionado con su finalidad. La costumbre de grabar el nombre de la unidad militar sobre material latericio no aparece hasta mediados del siglo I d.C., si bien existen significativas diferencias de unas a otras provincias y de unos a otros cuerpos. Aunque las dataciones se han establecido a partir de los datos de los textos clásicos relativos a la presencia y desplazamiento de determinadas legiones, los ejemplos más antiguos parecen encontrarse en Germania Superior durante la década de los años cuarenta del siglo I d.C. ${ }^{157}$ Uno de los ejemplares más antiguos parece ser una marca incisa de la legio II Augusta procedente de Estrasburgo, unidad que en el 43 d.C. se desplaza desde el continente hacia Britania. ${ }^{158}$ Entre las primeras unidades que sellan sus producciones se encuentra también la legio IIII Macedonica, que en el 39 d.C. se traslada desde Hispania a Germania Superior, donde la encontramos establecida en el 43 d.C. Sus sellos son semicirculares, con orbiculus, aunque también conocemos ejemplares en cartela rectangular. Sellos de esta legión se documentan en su campamento de Mogontiacum (Maguncia), ${ }^{159}$ en Oedenburg (Biesheim, Alsacia) ${ }^{160}$ y en el

\footnotetext{
153 Morillo et alii 2006, 315-319.

154 SteinBy 1975, 19.

155 Perestrelo 1998; ID. 2008, 60-61, fig. 8.

156 Szilagyi 1972; Peacock 1987; Brandl 1999, 30-32; Kurzmann 2006, 201-208.

157 PEACOCK 1987, 137.

158 Forrer 1935, fig. 3a.

159 BAATz 1962, 50-52.

160 Petry 1974, 373.
} 
fuerte de Hofheim. ${ }^{161}$ Recientemente se ha dado a conocer un interesante conjunto de sellos de la IIII Macedónica procedentes de Oppenheim, localidad situada cerca de Maguncia. ${ }^{12}$ Otras unidades que sellaron en época claudio-neroniana en Germania Superior fueron la I Germánica, XIV Gémina, XXII Primigenia y XXI Rapax. ${ }^{163}$ En provincias como Pannonia, la costumbre se introduce a partir del periodo flavio ${ }^{164} \mathrm{y}$ en Britannia se retrasa hasta finales del siglo I d.C. ${ }^{165}$

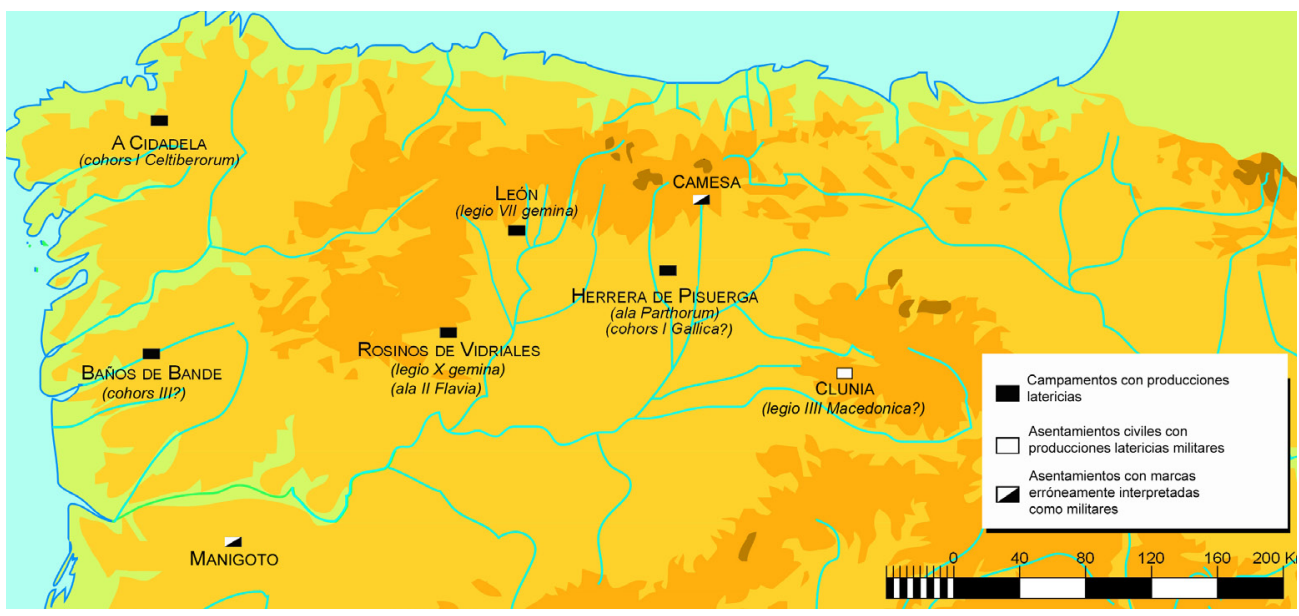

Fig. 17. Distribución de las marcas militares en Hispania.

Por lo que respecta a Hispania, de nuevo se ha recurrido a los datos históricos para tratar de establecer el marco temporal en que se desarrollan las primeras producciones militares selladas (Fig. 17). Sin embargo los datos disponibles en las fuentes clásicas son mucho más parcos que en el caso de Germania, lo que no facilita la cuestión. Siempre se ha considerado que las estampillas más antiguas fueron las empleadas por la legio X gemina en su campamento de Rosinos de Vidriales. Ya hemos señalado más arriba que no se descarta que dicha unidad, que permanece de guarnición en este lugar hasta el 63 d.C., hubiera sellado sus producciones antes de dicha fecha, cuando se desplaza hacia Carnuntum (Panonia). ${ }^{166}$ Esta hipótesis adelantaría el sellado militar en Hispania hacia parámetros temporales semejantes a Germania Superior, 10 o 20 años antes que en otras provincias septentrionales militarizadas como Germania Inferior, Raetia o Pannonia, lo que parece improbable. Más aún cuando la otra unidad estacionada en Hispania durante este mismo periodo, la legio VI victrix, no marca sus producciones en su campamento de León.

161 Ritterling 1913, 93, fig. 20.

162 DOLATA 2000; ID. 2001, 127-131.

163 KurZmann 2006, 202-204.

164 LÖRINCZ 1994, 115-117.

165 McWhirr 1979, 253-257; Brodribi 1987, 118; WARry 2010, 127.

166 Martin Valls et alii 2002, 150. 
En el año 68 d.C. la Legión X regresa brevemente a Hispania, para marchar definitivamente en el 69/70 d.C. Wahl se muestra partidario de que los sellos de la legión constatados en Rosinos correspondan a este segundo periodo de establecimiento. ${ }^{167}$ $\mathrm{Su}$ principal argumento es la ausencia de estampillas de la Legión X en Carnuntum en el periodo comprendido entre el 63 y 68 d.C. No cabe duda de que su estancia en Panonia pudo poner en contacto a la legio X gemina con la costumbre del sello militar y más tarde trasplantarlo a la provincia tarraconense. Pero si fuera así sería lógico hallar marcas de esta unidad en su campamento de Carnuntum a su estancia entre el 63 y el 68 d.C., lo que no se ha podido verificar. ${ }^{168}$ Por lo tanto, no puede confirmarse esta hipótesis de la transmisión directa de la estampilla militar desde Panonia hacia Hispania, aunque la presencia de marcas de la legio X gemina en Rosinos confirma que dicha unidad selló algunas de sus producciones, seguramente entre el 68 y 69/70 d.C. A esta segunda fase de ocupación del yacimiento de Rosinos podría corresponder el empleo de material latericio sellado y tal vez la muralla pétrea. Como ya hemos señalado, la inexistencia de una cronoestratigrafía completa en este yacimiento no permite avanzar más en esta cuestión.

Con posterioridad a su partida de Hispania, la legión conserva la tipología de sellos ya empleados en Rosinos de Vidriales, tal y como confirman los hallazgos de su campamento de Nimega. ${ }^{169}$

Ya hemos apuntado que recientemente se han publicado varias estampillas procedentes de Clunia atribuidas a la legio IIII Macedonica ${ }^{170}$ que nos obligan a replantear la cuestión del origen del sellado militar en Hispania. Aunque sólo una de ellas está completa, parece no haber dudas en identificar dicha unidad, asociada en este caso a un posible trabajador "MA". Aunque no conocemos sellos idénticos de la unidad, tanto el tipo de marca, semicircular, como la forma de las propias letras, nos remiten a los sellos de la legio IIII documentados en Germania a partir del 43 d.C. ${ }^{171}$ La ausencia de materiales sellados en el campamento de la unidad en Herrera de Pisuerga (Palencia) ${ }^{172}$ nos lleva a plantearnos si estamos ante materiales posteriores a la partida de la Legión IIII hacia Germania en el 39 d.C., desplazados a varios miles de kilómetros de sus centros productores en Mogontiacum (Maguncia), o si el sellado se enmarca dentro de una acción puntual de la legión durante su estancia en Hispania, que requería por algún motivo identificar su producción fuera de sus castra. En este caso estaríamos ante la primera marca militar conocida en todo el Imperio, anterior al 39 d.C. y precisamente en la provincia tarraconense. La parquedad del registro y la carencia de indicadores estratigráficos fiables no permite pronunciarse con mayor rotundidad pero no debemos olvidar que es precisamente la legio IIII Macedonica uno de los cuerpos militares, si no el primero, que comienza a sellar su producción al llegar a Germania entre el 39 y el 43 d.C.

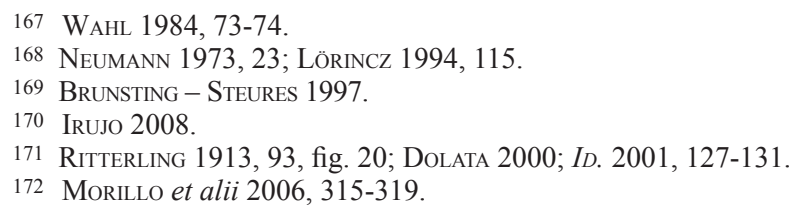


No cabe duda de que la producción para la que existe una datación más fiable es la de la legio VII gemina en su campamento de León, fundado a partir del 73/74 d.C. tras la llegada de esta unidad desde Germania Superior. Ya hemos apuntado que sellos de la misma anteriores a los fabricados en Hispania se conocen en el centro alfarero de Rheinzabern, ${ }^{173}$ Maguncia ${ }^{174}$ y, posiblemente, Carnuntum ${ }^{175}$ Este último, que se formula como L (egio) VII, teniendo en cuenta que la legión estaría asentada brevemente en este lugar durante el año 68 d.C., antes incluso de su refundación como VII gemina tras la segunda batalla de Bedriacum, sería presumiblemente el más antiguo. Las estampillas serían trasladadas a la Península Ibérica con sus rasgos tipológicos y paleográficos ya definidos desde el campamento de Carnuntum.

\section{Producción, dispersión y finalidad de los sellos militares hispanos}

Al definir el panorama de los sellos militares hispanos ya hemos ido apuntando el estado de la investigación sobre cuestiones productivas relativas al material latericio militar. No vamos a volver sobre aspectos generales relativos a la fabricación de este tipo de material, ${ }^{176}$ pero es preciso detenerse en algunos detalles propios de las figlinae militares hispanas.

Por lo que se refiere a las abreviaturas empleadas por las officinae establecidas por diferentes cuerpos del ejército, no cabe duda de que el corpus más completo y dilatado a lo largo del tiempo corresponde a la legio VII gemina. Predominan los sellos en relieve, aunque aparecen también algunos incisos. Las marcas son generalmente rectangulares, si bien se constatan también los lados menores redondeados, las tabulae ansatae y la orla en espiga. Se han documentado marcas retrógradas y estampillas que combinan una parte en sentido dextrorsum y la otra retrógrada. Algunas tejas y ladrillos presentan varias marcas realizadas con el mismo punzón. La palabra legio se abrevia habitualmente como "L", "LE" o "LEG"; el numeral VII siempre está presente; el primer cognomen gemina, generalmente mencionado, se abrevia como "G", "GE" o "GEM"; los apelativos pia y felix se indican con la letra inicial ("P" y "F" respectivamente). Los cognomina derivados de nombres imperiales se suelen simplificar al modo habitual, con las tres o cuatro primeras letras que lo identifican ("A" ó "An"= Antoniniana $;$ "Max"= Maximiniana $;$ "Gor"= Gordiana $;$ "Phil"= Philippiana, etc.). A veces aparecen sellos múltiples sobre las mismas piezas, en especial tégulas. No vamos a profundizar más en el estudio epigráfico y paleográfico que ya ha sido presentado por otros especialistas. ${ }^{177}$

El resto de producciones (legio X gemina, cohors I Celtiberorum, ala Parthorum, ala II Flavia) presentan variantes muy semejantes. También en este caso casi todos

173 Ludowici 1912, 115-116 y 125-127; Dolata 2001, 132-135, nº XVI 1-11 y XVI 14-38.

174 Dolata 2001, 132-135, n XVI 12 y 13.

175 Neumann 1973, 36.

176 Juan Tovar - Bermúdez 1995; Bermúdez - Juan Tovar 1995; Tsiolis 1997; Rico 2000; Roldán Gómez 2008.

177 cf. Le BoHeC 1992. 
los sellos se disponen en cartelas rectangulares con letras en relieve, donde los nombres de la unidad siempre aparece abreviada ("L", para legio; "C", "COH" o "CHO" para cohors; "A", "AL" o "ALA", para ala). Los numerales siempre están presentes, y los apelativos se abrevian ("G", para gemina; "PAR", para Parthorum; "C", para Celtiberorum; "F", para Flavia). Además de León, marcas en tabula ansata se documentan sólo en Herrera de Pisuerga entre los materiales del ala Parthorum. ${ }^{178}$ Solamente las posibles marcas de la legio IIII Macedonica procedentes de Clunia se presentan en forma de estampilla semicircular con orbiculus.

Los punzones empleados para grabar sobre el material latericio podían ser de madera, asta o hueso, arcilla e incluso metal. ${ }^{179}$ No se ha recuperado ninguno en Hispania. A tenor del tamaño de las marcas, sus dimensiones pueden variar. En León, donde se conoce casi un centenar de variantes diferentes de punzones, la altura de las estampillas rectangulares oscila entre 2 y $3 \mathrm{~cm}$, si bien la mayoría presenta en torno a $2,8 \mathrm{~cm}$. Su longitud está entre 9 y $11 \mathrm{~cm}$, aunque depende mucho de la marca empleada y los apelativos presentes a lo largo del tiempo. ${ }^{180}$ Algunos de ellos llegan a $12-13 \mathrm{~cm}$. Otros yacimientos, como Cidadela o Herrera, no proporcionan datos sobre las dimensiones de los sellos. Los sellos del material latericio procedente de Petavonium son muy similares a los de León, con una altura de 2,4- 3,1 cm y una anchura de 6-9 cm. ${ }^{181}$ En el caso de las estampillas semicirculares de la Legión IV Macedónica halladas en Clunia la altura es de 2,4 cm, mientras el diámetro es $11,1 \mathrm{~cm}$.

Una de las novedades más significativas de los últimos años es la confirmación de la existencia de sellos militares en los que figuran nombres propios unidos a la propia marca. Ya García y Bellido reseñaba algunas de estas marcas peculiares, ${ }^{182}$ pero trabajos posteriores han confirmado y ampliado la nómina. ${ }^{183}$ Conocemos así varias abreviaturas personales cuyo desarrollo ha planteado Le Roux como cognomina en genitivo: Pri(mi), Sev(eri), Mas(culi o cli), Luci, Reb(urri), Vic(toris) o Meti Cecilia(ni) ${ }^{184}$ (Fig. 11, $\mathbf{n}^{\mathbf{0}}$ 1-5), al que debemos añadir Val(eri) Pa [...], recientemente constatado en una cartela en tabula ansata ${ }^{185}\left(\mathbf{F i g} .11, \mathbf{n}^{\mathbf{0}} \mathbf{6}\right)$. Este mismo autor ${ }^{186}$ plantea que debemos interpretar en este sentido la supuesta marca Qui(ntili) o Qui(ntiliani) que García y Bellido atribuía al emperador Quintilo, ${ }^{187}$ a la que hemos añadido en el presente trabajo el nombre $\mathrm{Cl}$ (audii), que García y Bellido interpreta como abreviatura en genitivo de Claudio II. En las marcas de Clunia este podría ser también el caso de Ra(cilius?), asociado supuestamente a la legio IIII. ${ }^{188}$

\footnotetext{
178 Pérez González 1996, 99, fig. 2, 1.

179 BrodribB 1987, 118-120.

180 Morillo - SAlido 2013, en prensa.

181 Martín Valls et alii 2002.

182 García y Bellido 1970, 598.

183 Liz Guiral - Amaré 1993, 56.

184 Le Roux 1999, 118.

185 CAMPOMANes 2006, 447, fig. 6.

186 CAmpomanes 2006, 453.

187 García y Bellido 1970, 597.

188 IRUjo 2008, 109.
} 
Tanto Liz y Amaré ${ }^{189}$ como Le Roux ${ }^{190}$ interpretan estos nombres como pertenecientes a trabajadores vinculados al proceso productivo de los talleres. Recientemente Kurzmann ha recopilado las marcas de este tipo sobre material latericio, planteando que dichos trabajadores son siempre soldados e immunes figlinae, aunque también pueden aparecer oficiales supervisores. ${ }^{191}$ En este sentido serían semejantes a otros nombres propios que aparecen en inscripciones en cursiva, como el Valerius documentado sobre producciones de la legio VII en Candanedo de Fenar. ${ }^{192}$ Tal vez en este mismo sentido habría que interpretar la inscripción en cursiva: Rufus mil(es) $L$ (egionis) X G(eminae) $f$ (ecit) procedente de Rosinos de Vidriales, que nos ilustra sobre la categoría jurídica del trabajador. ${ }^{193}$

Entre las marcas en cursiva también destacan algunos ejemplos interesantes como la marca IMP CAES/T AELIO HA inscrita sobre un ladrillo bessalis procedente de las termas de León, que alude claramente a Antonino Pío. ${ }^{194}$ En otro de los ladrillos, en este caso de tipo pedal, recientemente publicados, procedente de las intervenciones en Puerta Obispo, aparece el numeral VI escrito también con un punzón, que hemos interpretado tal vez como el indicativo del número de posición de una pila de hipocausto, que evidentemente no está pensada para ser vista tras la construcción del edificio. ${ }^{195}$

Junto a los sellos militares propiamente dichos, han llegado hasta nosotros varias marcas de producción realizadas con los dedos, seguramente practicadas por diferentes operarios para contabilizar las piezas elaboradas por cada uno. ${ }^{196}$ En León se constata la presencia de círculos $\left(\mathrm{n}^{\circ} 42\right.$ y 60$)$, aspas $\left(\mathrm{n}^{\mathrm{o}} 3\right)$, ondulaciones $\left(\mathrm{n}^{\mathrm{o}} 35\right)$ y líneas rectas $\left(\mathrm{n}^{\mathrm{0}} 55\right.$ y 79$)$, sobre tejas y ladrillos. ${ }^{197}$

Uno de los problemas fundamentales en cualquier estudio de material latericio es que en pocas ocasiones se da a conocer el análisis de conjunto de piezas selladas y sin marca. La atención obviamente se centra en las primeras. Esta tendencia impide conocer una cuestión productiva de tanta importancia como el porcentaje del material estampillado en relación con el total y su aplicación diferenciada sobre tejas y ladrillos. En el caso de León dichos porcentajes sólo se han dado a conocer en el reciente análisis que hemos publicado sobre Puerta Obispo. ${ }^{198}$ La totalidad de las ímbrices se encuentran selladas, así como un elevado porcentaje de las tégulas (un 80\%). Respecto a los ladrillos, más de la mitad (un 60\%) presenta estampilla. En el fuerte de Cidadela el porcentaje se reduce levemente, hasta un 58,6\%. ${ }^{199}$

\footnotetext{
189 Liz Guiral - Amaré 1993, 56.

190 Le Roux 1999, 118.

191 KurZmann 2006, 215-232.

192 Gutiérrez GonZÁlez 1985, 159.

193 Martín VALLS et alii 2002, 148-150.

194 García y Bellido 1970, 577, fig. 20.

195 Morillo - SAlido 2013, en prensa.

196 BrodribB 1987, 99-105.

197 Morillo - SAlido 2013, en prensa.

198 Morillo - Salido 2013, en prensa.

199 Carlsson-Brandt 2011, 170.
} 


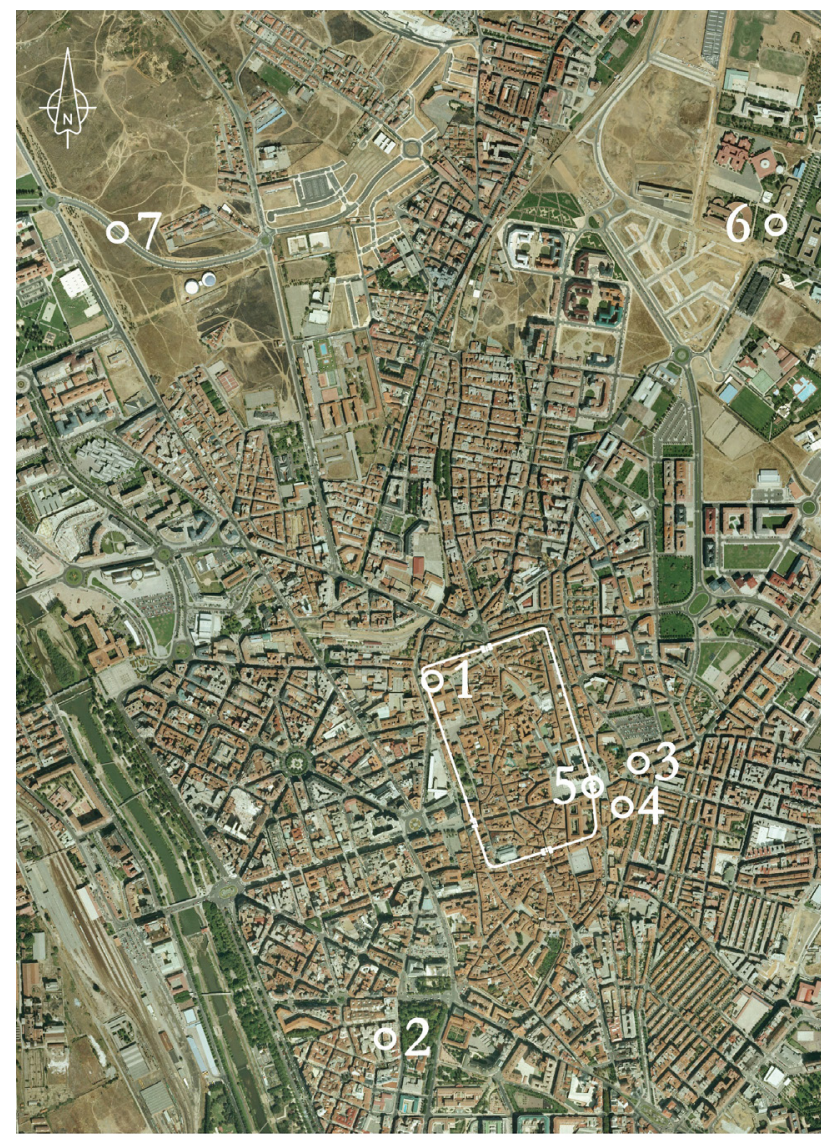

Fig. 18. Dispersión de las marcas latericias publicadas de la legio VII gemina en su campamento de León y sus cercanías. La imagen aérea ha sido obtenida de Google Earth.

La comparación de dichos porcentajes con los que presentan materiales de otros acantonamientos militares romanos de las fronteras septentrionales ofrece interesantes datos, aunque debamos mantener cierta cautela ya que los porcentajes de dichos establecimientos se calculan en su mayoría sobre ejemplares completos y varían de uno a otro edificio. ${ }^{200}$ En acantonamientos de las provincias renanas, como Vetera Castra I, el material estampillado alcanza el 77,5\%, mientras en Britania se mueve en porcentajes de entre el 0,5 y el $5 \% .{ }^{201}$ De cualquier forma, en León el porcentaje de sellado es mucho mayor que en cualquiera de ellos, incluido Cidadela. Estas variaciones pueden obedecer tanto a cuestiones cronológicas, como a la mayor o menor necesidad de distinguir el material militar respecto al ámbito civil, sin olvidarnos de la propia tradición castrense de cada región.

200 BoON 1984, 16-17.

201 v. KuRZMANN 2006, 27-28. 


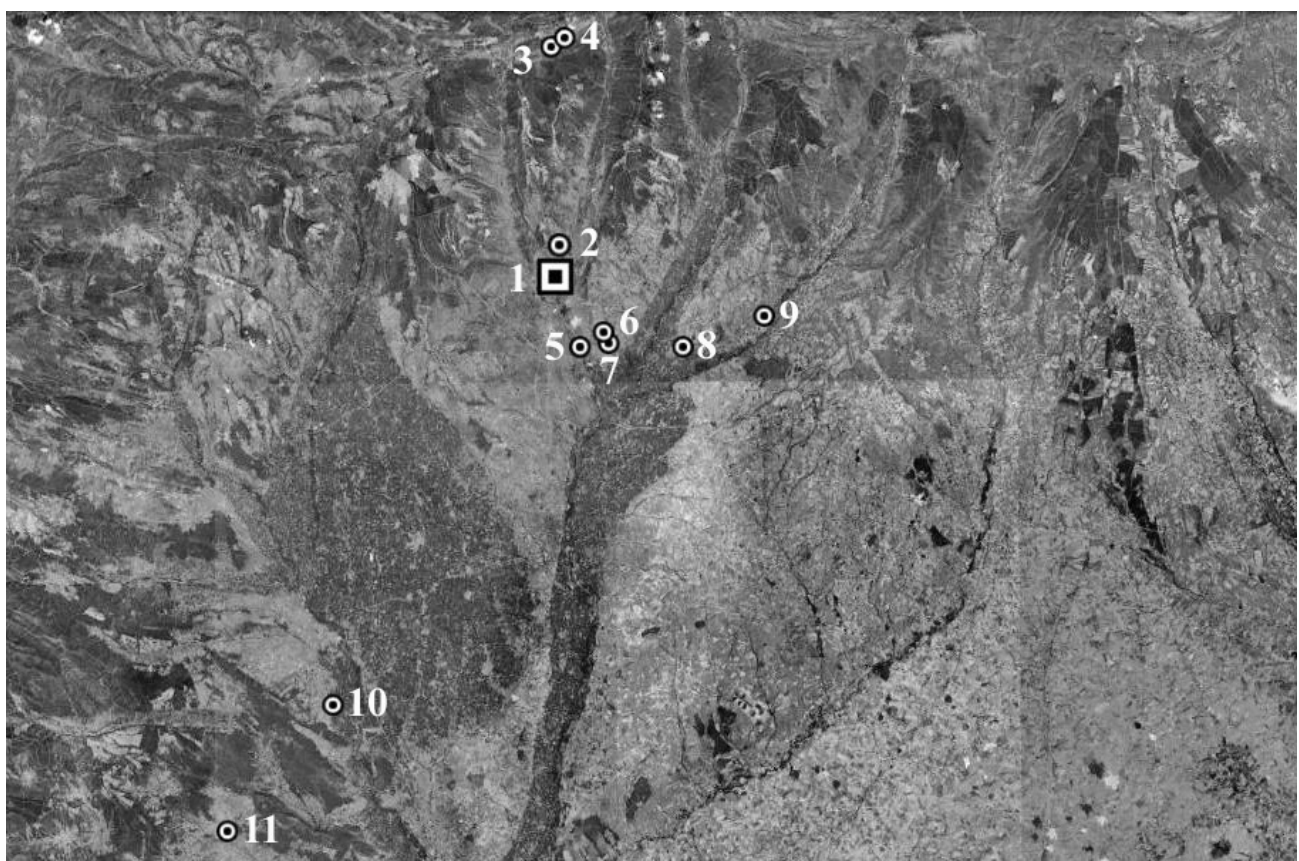

1. Campamento romano de la legio VII Gemina (León)

2. Villa romana de Navatejera

7. Valdesogo de Abajo

3. Rabanal de Fenar

8. Ciudad romana de Lancia (Villasabariego)

4. Candanedo de Fenar

5. Villa romana de Marialba

6. Valdesogo de Arriba

9. San Miguel de la Escalada

10. Villa romana de Quintana del Marco

11. Campamento romano de Rosinos de Vidriales

Fig. 19. Dispersión de las marcas de la legio VII gemina en el entorno de León. La imagen aérea ha sido obtenida de Google Earth.

El hallazgo de una concentración excepcional de material latericio sellado, así como los restos de dos hornos, en el valle de Fenar, a una treintena de $\mathrm{km}$ al norte de la actual ciudad de León, ${ }^{202}$ ha permitido situar en esta zona uno de los talleres que abastecían al campamento de la VII Gémina, aunque sin duda existieron talleres mucho más próximos al recinto militar. ${ }^{203}$ Esta sería la única officina conocida hasta el momento.

Se suele aceptar que el ejército romano marca sus tejas y ladrillos como signo de autoridad y propiedad, seguramente para distinguirlo de las producciones civiles, ${ }^{204}$ pero no como un indicativo de registro o exención fiscal, tal y como indicaba Szilágyi. ${ }^{205}$ La distribución de la producción militar está en principio localizada y confi-

202 GutiéRREZ 1985, 126-127 y 155-160.

203 Morillo 2008, 179.

204 Brodribi 1987, 117; PeAcock 1987, 137.

205 Szilágyi 1972, 434. 
nada dentro de los límites marcados por la jurisdicción del ejército. ${ }^{206}$ Esto ha llevado a algunos autores a intentar reconstruir el territorium militaris de las diferentes unidades partir de la dispersión de sus marcas latericias, cuestión en revisión en la actualidad, al igual que el propio concepto de territorio militar. ${ }^{207} \mathrm{La}$ incógnita sigue siendo por qué algunas unidades marcan sus producciones mientras otras no lo hacen y por qué el mismo cuerpo sella sus producciones en determinado momento, mientras cesa esta actividad en otros periodos. Es posible que dicha costumbre sea una manera de marcar la propiedad o jurisdicción militar cuando existen producciones civiles concurrentes de las que distinguirse, pero innecesaria cuando dicho problema no se plantea. En el caso hispano, en aquellos establecimientos militares en los que se verifica una considerable presencia de materiales de talleres civiles, como Bande, ${ }^{208}$ o el fuerte del Ala II Flavia en Rosinos de Vidriales, ${ }^{209}$ no parece existir una producción militar de importancia. Por el contrario, allí donde existen elevados porcentajes de sellos y ladrillos de officinae militares, como León y Cidadela, apenas se introducen los fabricantes civiles.

A pesar de tratarse de producciones destinadas a la construcción y el mantenimiento de las infraestructuras del campamento (termas, alcantarillado, suministro de agua, etc.), su ámbito de dispersión se extiende al hinterland inmediato (Fig. 18 y 19). En el caso de León, además de los propios centros productivos como Candanedo y Rabanal de Fenar, ${ }^{210}$ se detecta en villas como Navatejera o Marialba, ${ }^{211}$ además de yacimientos de carácter indeterminado como San Miguel de la Escalada, ${ }^{212}$ Valdesogo de Arriba y Valdesogo de Abajo. ${ }^{213}$ A algunos de ellos deben llegar acarreados como material constructivo en momentos muy posteriores a su elaboración (Navatejera, Marialba, Escalada), al igual que sucede dentro del propio campamento, donde se emplean tejas y ladrillos sellados reutilizados en las necrópolis tardorromanas del Campus de Vegazana ${ }^{214}$ y el monasterio de San Claudio. ${ }^{215}$

Las producciones de la legio VII gemina alcanzan otras zonas con fuerte presencia de dicha unidad (Fig. 19), como el fuerte del ala II Flavia en Rosinos de Vidriales, ${ }^{216}$ que puede haber sido ocupado temporalmente por una guarnición de la unidad legionaria. Llegan también a asentamientos civiles como Asturica $^{217}$ y la cercana villa de Los Villares de Quintana del Marco. ${ }^{218}$ En estos casos es difícil pronunciarse sobre si llegan a manos de la propia unidad o como material constructivo trasportado en momentos posteriores.

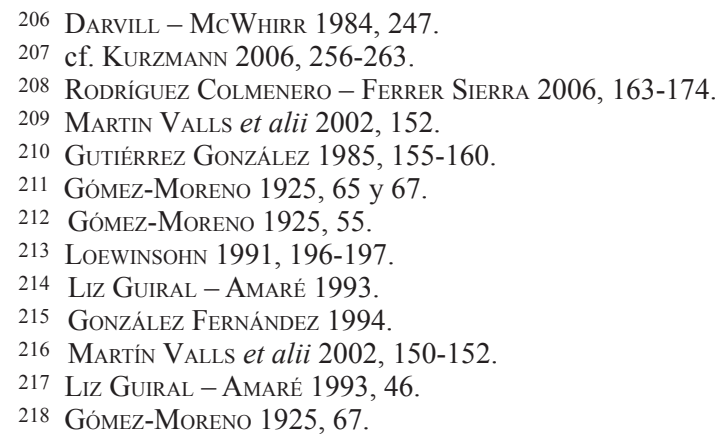




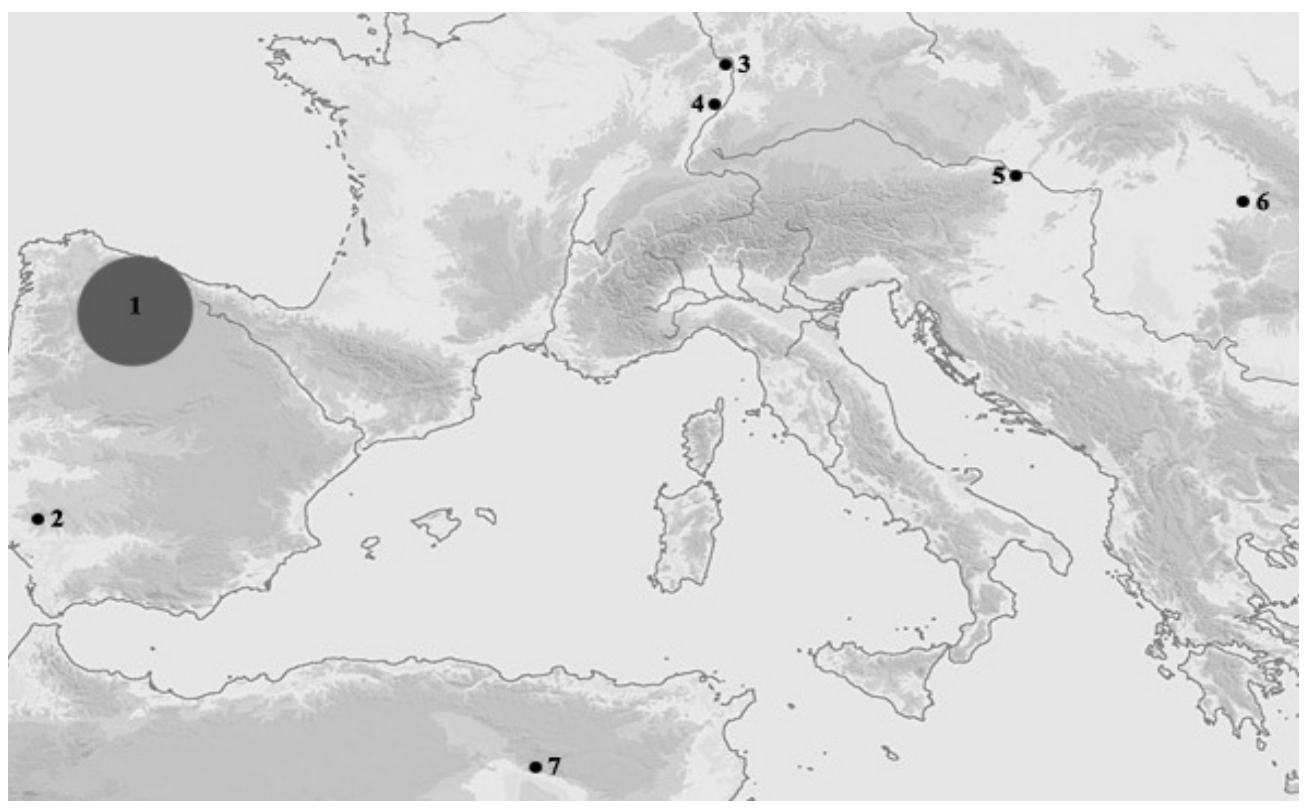

1. Zona de influencia de la legio VII Gemina en el entorno de León

2. Ciudad romana de Italica (Santiponce, Sevilla)

3. Campamento romano de Mogontiacum (Maguncia, Alemania)
4. Campamento romano de Rheinzabern (Alemania)

5. Campamento romano de Carnuntum (Austria)

6. Campamento romano de Porolissum (Rumania)

7. Campamento romano de Lambaesis (Argelia)

Fig. 20. Dispersión de las marcas de la legio VII gemina en el Imperio Romano.

Puntualmente alcanzan otras provincias. En la Bética se han constatado en Itali$c a{ }^{219}$ Asimismo se constatan fuera de la Península, en relación con la presencia de la legio VII gemina o sus destacamentos en estos lugares. ${ }^{220}$ Además de las localizadas en Germania y tal vez Panonia, aspecto del que ya nos hemos ocupado, evidencias epigráficas de la misma se conocen en Lambaesis, campamento base de la legio III Augusta y su entorno. ${ }^{221}$ El papel de la VII Gémina habría sido posiblemente reforzar a esta última unidad, quizá durante el reinado de Adriano y los inicios del de Antonino Pío, momento de una situación compleja en la región ${ }^{222}$ (Fig. 20).

$\mathrm{Su}$ actuación durante las campañas dácicas de Trajano parece ser también segura, tal y como parecen atestiguar varias tegulae con el sello de la legión halladas en

219 García y Bellido 1970, 592, fig. 52, 22; ID. 1979, 22, nota 36, fig. 12. La presencia de dicha unidad en Itálica se ve refrendada por una inscripción (CIL II 1126) y otra posible (EE VIII, 92), que en su día se publicó como procedente de Villafranca de los Barros (Badajoz), y ha sido recientemente reinterpretada como italicense (CILA 2, 406; PALAo 2006, 83 y 307).

220 Morillo 2005, 28-29.

221 García y Bellido 1950, 463-464; Roldán 1974, 474, no 722; Palao 1998, 169-171.

222 Palao 1998, 168. 
Porolissum. ${ }^{223} \mathrm{Tal}$ vez su experiencia con las explotaciones auríferas hispanas fue el motivo de su participación en la conquista de un territorio que era preciso prospectar y cuya explotación minera era necesario planificar.

Queda por determinar si a algunos de estos lugares han llegado transportados por miembros de la propia legión o han sido fabricados específicamente en el lugar de destino. Más difícil parece aceptar que los materiales militares se muevan a través del comercio, al menos en parámetros temporales próximos a su momento de fabricación. Dicha casuística pudo verificarse en momentos muy posteriores, donde el material llega como elemento constructivo habiendo perdido el sentido originario de la estampilla.

El material latericio fabricado por otros cuerpos militares estacionados en Hispania no se documenta fuera del campamento al que estaba destinado. Un caso excepcional sería el de las posibles marcas de la legio IIII Macedonica de Clunia, del que ya nos hemos ocupado.

De cualquier forma, la presencia de marcas ofrece una información fundamental para conocer los movimientos militares. Pero la existencia de algunos sellos no necesariamente implica que dicha unidad se haya estacionado en el lugar de dicho hallazgo. ${ }^{224}$

\section{Consideraciones finales}

El análisis de las producciones con estampilla militar conocidas en la actualidad permite aclarar cuestiones relativas a la fabricación y abastecimiento de este material constructivo a las tropas desplegadas en Hispania durante el Alto Imperio. Se constatan producciones vinculadas a dos cuerpos legionarios, la Legión VII Gémina y la legión X Gémina, estacionados en León y Rosinos de Vidriales respectivamente, además de varias unidades auxiliares: ala Parthorum, cohors I Celtiberorum y ala II Flavia, acantonadas en Herrera de Pisuerga, Cidadela y Rosinos de Vidriales. Se han publicado también algunas marcas cuya identificación militar aún plantea cuestiones. Entre ellas destacan las posibles estampillas de la legio IIII Macedonica halladas en Clunia.

La aparición de los primeros sellos militares sobre material latericio hispano tiene lugar durante el periodo julioclaudio, pero la adopción generalizada de esta costumbre se verifica a partir del periodo flavio, unido al establecimiento de la legio VII gemina en León, y la creación de una red de fuertes auxiliares de dicha unidad.

Esta unidad ofrece el corpus más numeroso de estampillas sobre tejas y ladrillos, cubriendo un marco temporal que se extiende entre el 74 y el 251 d.C. Se han documentado cientos de ejemplares, cuyos sellos se han agrupado en 11 variantes constatadas.

El momento en que tiene lugar el origen de este fenómeno dista mucho de estar aclarado, así como las vías a través de las cuales la costumbre se instaura en la Península Ibérica. La legión que parece desempeñar un papel fundamental en esta cuestión

223 Gudea 1978, 65-75; Le Roux 1981, 119-200; Abascal 1986, 319-322.

224 KurZMANN 2006, 4. 
parece ser la legio X gemina, pero a tenor de los restos conservados en su base campamental de Rosinos de Vidriales no podemos establecer el momento concreto en que comenzó a firmar sus producciones. Tal vez tuvo lugar hacia el 68 d.C. La presencia de varias posibles marcas de la legio IIII Macedonica en Clunia, muy semejantes a los sellos de dicha unidad dispersos por la Germania Superior a partir del 39/43 d.C., no tuvo al parecer ninguna repercusión sobre otras unidades militares hispanas coetáneas, que siguieron sin firmar sus producciones durante varias décadas.

Una de las cuestiones más novedosas de los últimos años ha sido la identificación de nombres propios asociados a los de las unidades militares, especialmente a la legio VII gemina, dentro de las propias estampillas. Nos encontramos sin duda ante trabajadores militares vinculados al proceso productivo de los talleres establecidos por las autoridades castrenses. Por otra parte, la difusión de este tipo de material hacia lugares a veces muy alejados de sus centros productores sigue sin estar aclarada convenientemente. Y seguimos sin conocer ningún taller destinado a la fabricación de estos materiales.

El principal problema que subsiste en el análisis de este tipo de material es el empleo de dataciones históricas a partir de los datos de las fuentes clásicas. Apenas se han publicado ejemplares en contextos arqueológicos en posición primaria, a lo que contribuye sin duda la intensa reutilización de la que son objeto tejas y ladrillos romanos altoimperiales en épocas posteriores. Pocos edificios militares se conservan en pie, lo que permitiría asociar determinadas marcas a una fase constructiva concreta. Uno de los mejores ejemplos lo constituye la intervención en el solar leonés de Puerta Obispo, que recientemente hemos dado a conocer. ${ }^{225}$ Los análisis arqueométricos podrían contribuir a determinar talleres y fases constructivas. Pero tal y como hemos visto en un reciente trabajo, ${ }^{226}$ a veces se muestran inoperantes por motivos derivados de las características del propio proceso de fabricación cerámica.

\section{Bibliografía}

Abascal, J. M. (1986): "La Legio VII Gemina. Balance de la investigación y perspectivas”, [en] I Congreso Internacional Astorga Romana I, Astorga, 317-328.

AJA, J. R.

(2001): “¿Presencia militar romana en Cantabria? Una propuesta de revisión a la baja”, [en] Actas del I Congreso Internacional de Historia Antigua: La Península Ibérica hace 2000 años, Valladolid, 165-172.

(2007): "La epigrafía de la cohors I Celtiberorum", [en] M. Mayer - G. Baratta - A. Guzmán Almagro (eds.), Acta XII Congressus Internationalis Epigraphiae Graecae et Latinae, Barcelona, 23-30.

Amaré Tafalla, M T. T. Álvarez Vega, E. (2006): "Material latericio de la legio VII procedente del polígono de La Palomera (León)", [en] A. Morillo (ed.), Arqueología Militar Romana en Hispania. Producción y abastecimiento en el ámbito militar, León, 725-732.

225 Morillo - SALIDo 2013, en prensa.

226 Morillo 2012, en prensa. 
ArCe, J. (1979): Caesaraugusta, ciudad romana, Zaragoza.

BAATZ, D. (1962): Mogontiacum: neue Untersuchungen am römischen Legionslager in Mainz (=Limesforschungen 4), Berlin.

Beltrán, M. - Fatás, G. (1998): Caesar Augusta, ciudad romana. Historia de Zaragoza, II, Zaragoza.

Bermúdez, A. - Juan Tovar, L. C. (1995): "Las fuentes clásicas en el estudio de las industrias cerámicas. Una introducción”, Anuario de la Universidad Internacional SEK 1, 23-35.

Blázquez Cerrato, C. - CARretero, S. (2006): “Cronologías estratigráficas: cerámica y monedas", [en] Ma P. García-Bellido (coord.), Los campamentos romanos en Hispania (27 a.C.-192 d.C.). El abastecimiento de moneda (=Anejos de Gladius 9), Madrid, 195-218.

Boon, G. C. (1984): Laterarium Iscanum. The antefices, bricks and stamps of the Second Augustan Legion, Cardiff.

BRANDL, U. (1999): Untersuchungen zu den Ziegelstempeln römischer Legionen in den nordwestlichen Provinzen des Imperium Romanum: Katalog der Sammlung Julius B. Fritzemeier (=Passauer Universitätsschriften zur Archäologie 6), Rahden-Westfalen.

BrodribB, G. (1987): Roman Brick and Tile, Gloucester.

Brunsting, H. - Steures, D.C. (1997): "The brick stamps and the occupation history of the legionari fortress at Nijmengen", [en] W. Groenmann-Waatering - B. L. Van Beek - W. J. H. Willems - S. L. Wynia (eds.), Roman Frontier Studies 1995, Proceedings of the XVIth International Congress of Roman Frontier Studies, Oxford, 323-329.

CaAmaño Gesto, J. M.

(1984/85): "La Cohors I Celtiberorum y su campamento de Cidadela (Sobrado dos Monxes-Coruña)", Cuadernos de Estudios Gallegos 100,71-78.

(1989): "Estampillas de la Cohors I Celtiberorum, halladas en el campamento romano de Cidadela", Gallaecia 11, 209-228.

CAmpomanes, E. (2006): "El acueducto de la legio VII gemina y sus producciones latericias", [en] A. Morillo (ed.), Arqueología Militar Romana en Hispania. Producción y abastecimiento en el ámbito militar, León, 439-454.

Carlsson-Brandt Fontán, E. (2011): "El material constructivo latericio en el campamento romano de Cidadela (Sobrado dos Monxes, A Coruña)", Gallaecia 30, 167-180.

CARretero, S.

(2000): El campamento romano del Ala II Flavia en Rosinos en Vidriales (Zamora). La cerámica, Zamora.

(2006): "Petavonium (Rosinos de Vidriales, Zamora). Introducción histórica y arqueológica”, [en] Ma P. García-Bellido (coord.), Los campamentos romanos en Hispania (27 a.C.192 d.C.). El abastecimiento de moneda (=Anejos de Gladius 9), Madrid, 171-194.

Carretero, S. - Romero Carnicero, Mª V. (1996): Los campamentos romanos de Petavonium (Rosinos de Vidriales, Zamora), Zamora.

Cichorius, C.

(1893): “Ala", RE I, 1.

(1900): "Cohors", RE IV, 1.

Darvill, T. - McWhirr, A. (1983-1984): "Brick and tile production in Roman Britain. Models of economic organisation", World Archaeology 15, 239-261. 
DOLATA, J.

(2000): "Ein rösmisches Ziegeldach mit gestempelten Ziegeln in Oppenheim. Geochemische Referenz und Typengliederung von Ziegelstempel der legio IIII Macedonica", Oppenheimer Hefte 2, 40-53.

(2001): Römische Ziegelstempel aus Mainz und dem nördlichen Obergermanien. Archäologische und archäometrische Untersuchungen zu chronologischem und baugeschichtlichem Quellenmaterial (=Archäologisches Nachrichtenblatt 6, 3), Frankfurt am Main.

FernÁndez Freile, B. E. (2003): La época romana en León. Aspectos arqueológicos. Estudio arqueológico de un vertedero romano situado en la calle Maestro Copín c/v San Salvador del Nido en la ciudad de León, León.

FernÁndez OchoA, C. - Gil Sendino, F. (2008): "La villa romana de Veranes (Gijón, Asturias) y otras villas de la vertiente septentrional de la cordillera Cantábrica", [en] C. Fernández Ochoa - V. García Entero - F. Gil Sendino (eds.), Las villae tardorromanas en el occidente del Imperio: Arquitectura y función. IV Coloquio Internacional de Arqueología en Gijón, Gijón, 435-479.

Fernández Vega, P. A. (2010): “El enigma de Camesa-Rebolledo", Cuadernos de Campóo, época II, 7, 5-32.

Fernández Vega, P. A. - Peñil Mínguez, J. - Bustamante Cuesta, S. (2005): “Camesa-Rebolledo. ¿Vera Iuliobriga?”, Cuadernos de Campóo 42, 4-13.

Fitz, J. (1983): Honorific titles of Roman military units in the 3rd century, Budapest.

FORRER, R. (1935): Alsace romaine, Estrasburg.

García y Bellido, A.

(1950): "La Legio VII Gemina Pia Felix y los orígenes de la ciudad de León”, BRAH 227, 449-479.

(1959): “Cohors I Gallica Equitata Civium Romanorum”, Conimbriga 1, 29-40.

(1961): "El "Exercitus Hispanicus" desde Augusto a Vespasiano", AEspA 34, 114-160.

(1970): “Estudios sobre la Legio VII Gemina y su campamento en León”, [en] Legio VII Gemina, León, 569-600.

(1979): Colonia Aelia Augusta Italica (=Bibliotheca Archaeologica 2), Madrid.

García Guinea, M. A. - Robles, J. M. - Pérez González, C. - Puente, M. A. - Peñil, J. - Illarregui, E. (1985): "El yacimiento arqueológico de Rebolledo-Camesa (Valdeolea, Cantabria), campañas 1981-1982”, Sautuola IV, 197-310.

García Marcos, V. (2002): "Los campamentos romanos de León”, [en] A. Morillo (coord.), Arqueología Militar Romana en Hispania (=Anejos de Gladius 5), Madrid, 167-211.

Garzetti, A. (1970): “Legio VII Hisp(ana)”, [en] Legio VII Gemina, León, 331-336.

Gómez Moreno, M. (1925): Catálogo monumental de la provincia de León, Madrid.

GonzÁlez FernÁndez, Ma L. (1994): "Necrópolis tardorromana en el solar del Monasterio de San Claudio en León", Nvmantia 5, 107-126.

González García, J. M. - Pérez-Seone, J. M. (1989): “El Valle del Fenar: contribución al estudio de su poblamiento antiguo y medieval”, Tierras de León 29 (76), 69-98.

GudEA, N.

(1978): "Descoperiri archeologice si epigrafice mai vechi sau mai noi Porolissum", Acta Musei Porolissensis II, 65-75. 
(2001): "Die Nordgrenze der römischen Provinz Obermoesien: Materialien zu ihrer Geschichte (86-275 n. Chr.)", Jahrbuch des Römisch-Germanischen Zentralmuseums Mainz 48/2, 3-118.

Gutiérrez González, J. A. (1985): Poblamiento antiguo y medieval en la montaña central leonesa, León.

Hassall, M. (1979): “Military Tile-stamps from Britain”, [en] A. McWhirr (ed.), Roman Brick and Tile. Studies in Manufacture, Distribution and Use in the Western Empire (=BAR International Series 68), Oxford, 261-266.

ILlarRegui, E.

(1998): "Camesa-Rebolledo: asentamiento militar al sur de Cantabria”, [en] A. Rodríguez Colmenero (ed.), Los orígenes de la ciudad en el Noroeste Hispánico. Actas del Congreso Internacional, (Lugo, 15-18 de mayo de 1996), Lugo, vol. I, 559-583.

(1999): "La legio IIII Macedonica a través de los materiales arqueológicos", [en] Regio Cantabrorum, Santander, 179-183.

Irujo Lizaur, J. (2008): "Sellos sobre material latericio de la Legio IIII Macedonica en la Colonia Clunia Sulpicia”, Oppidum 4, 99-112.

Johnson, A. (1983): Roman Forts, London.

Jones, M. J. (1975): Roman Fort-defences to AD 117, with special reference to Britain (=BAR International Series 21), Oxford.

Juan Tovar, L. C. - Bermúdez, A. (1995): "La investigación sobre las industrias cerámicas de época romana en Hispania. El Programa Officina", Anuario de la Universidad Internacional SEK 1, 11-22.

KURZMANN, R.

(2005): "Soldier, Civilian and Military Brick Production: the question of private entrepreneurs tiling for the Roman army", Oxford Journal of Archaeology 24, 4, 405-414.

(2005a): "Soldiers or emperors? Some problems with imperial titles on military brickstamps", [en] Z. Visy (ed.), Limes XIX, Proceedings of the XIXth International Congress on Roman Frontier Studies, Pécs, 327-336.

(2006): Roman military brick stamps: A comparison of Methodology (=BAR International Series 1543), Oxford.

Le Bohec, Y. (1992): “Les estampilles de 1'armée romaine sur briques et sur tuiles”, Epigraphica 54, 43-62.

Le Roux, P.

(1981): "Inscriptions militaires et déplacements de troupes dans l'Empire romain", ZPE 43, 119-200.

(1982): L'armée romaine et l'organisation des provinces ibériques d'Auguste a l'invasion de 409, Paris.

(1999): "Briques et tuiles militaires dans la Péninsule Ibérique: problèmes de production et de diffusion", [en] M. Bendala Galán - Ch. Rico - L. Roldán Gómez (eds.), El ladrillo y sus derivados en la época romana, Madrid, 111-124.

(2000): "Legio VII Gemina (pia) felix", [en] II Congrés de Lyon sur l'armée romaine. Les légions de Rome sous le Haut Empire (1998), Lyon, 384-396.

Liz Guiral, J. - Amaré Tafalla, M. T. (1993): Necrópolis tardorromana del Campus de Vegazana, León. 
LoEwinsohn, E. (1991): "Las calzadas romanas en el entorno de Astorga I", Astorica 10, 187217.

LöRINZ, B. (1994): "I bolli laterizi militari in Pannonia. Risultati delle richerche chronologiche", [en] La Pannonia e L'Impero romano, Roma, 115-138.

LudowicI, W.

(1905): Stempel-Bilder römischer Töpfer: aus meinen Ausgrabungen in Rheinzabern, nebst dem II. Teil der Stempel-Namen 1901-1905 (=Katalog meiner Ausgrabungen in Rheinzabern 2), Jockgrim.

(1912): "Truppenziegeleien in Rheinzabern und leg. VII gemina am Rhein”, [en] Römische Ziegelgräber: Stempel-Namen, Stempel-Bilder, Urnen-Gräber (=Katalog meiner Ausgrabungen in Rheinzabern 1908-1912, 4), München, 115-116.

Macrea, M. (1945-1947): "Note au sujet des briqueteries en Dacie”, Dacia 11-12, 275-280.

Martín Valls, R. - Delibes de Castro, G. - Mañanes, T. (1975): Sobre los campamentos de Petavonium (=Studia Archeologica 36), Valladolid.

Martín Valls, R. - Romero Carnicero, Mª V. - Carretero, S. (2002): "Marcas militares en material de construcción de Petavonium", [en] A. Morillo (coord.), Arqueología Militar Romana en Hispania (=Anejos de Gladius 5), Madrid, 137-154.

McWhirr, A. (ED.) (1979): Roman Brick and Tile. Studies in Manufacture, Distribution and Use in the Western Empire (=BAR International Series 68), Oxford.

Morillo, A.

(1999): Lucernas romanas en la región septentrional de la Península Ibérica. Contribución al conocimiento de la implantación romana en Hispania (=Monographies Instrumentum 8), Montagnac.

(2000): "La legio IIII Macedonica en la Península Ibérica: el campamento de Herrera de Pisuerga (Palencia)", [en] Deuxième congrès de Lyon sur l'armée romaine: Les legions de Rome sous le Haut-Empire, Lyon, 609-624.

(2002): "Conquista y estrategia: el ejército romano durante el periodo augusteo y julioclaudio en la región septentrional de la península ibérica", [en] A. Morillo (coord.), Arqueología Militar Romana en Hispania (=Anejos de Gladius 5), Madrid, 67-94.

(2005): "Hispania en la estrategia militar del Alto Imperio: movimientos de tropas en el arco atlántico a través de los testimonios arqueológicos”, [en] C. Fernández Ochoa - P. García Díaz (eds.), III Coloquio Internacional de Arqueología en Gijón: Unidad y diversidad en el Arco Atlántico en época romana (=BAR International Series 1371), Oxford, 19-33.

(2006): “Abastecimiento y producción local en los campamentos de la región septentrional de la Península Ibérica”, [en] A. Morillo (ed.), Arqueología Militar Romana en Hispania. Producción y abastecimiento en el ámbito militar, León, 33-74.

(2006a): "Los Dióscuros y la legio VII gemina. Algunas reflexiones sobre el apelativo y el emblema de la legión", [en] A. Morillo (ed.), Arqueología Militar Romana en Hispania. Producción y abastecimiento en el ámbito militar, León, 745-758.

(2008): "Producciones cerámicas militares en Hispania", [en] D. Bernal - A. Ribera (eds.), Cerámicas hispanorromanas. Un estado de la cuestión, Cádiz, 275-293.

(2008a): "La implantación militar romana en el territorio de Cantabria durante el Alto Imperio", [en] J. R. Aja - M. Cisneros - J. L. Ramírez (eds.), Los cántabros en la Antigüedad. La historia frente al mito, Santander, 2008, 142-154. 
(2010): "Sistemas defensivos en los campamentos romanos de León", [en] V Congreso de Obras Públicas Romanas: Las Técnicas y las Construcciones en la Ingeniería Romana, Córdoba, 463-477.

(2012): "Manufacturas militares romanas en Hispania", [en] D. Bernal - M. Bustamante (eds.), Artífices idóneos. Artesanos, talleres y manufacturas en Hispania, Mérida (en pren$\mathrm{sa})$.

Morillo, A - Fernández IBÁÑEz, C. (2001-2002): “Un aplique decorativo con inscripción militar procedente de Herrera de Pisuerga (Palencia, España)", Journal of Roman Military Equipment Studies 12-13, 47-51.

Morillo, A. - García Marcos, V.

(2000): "Nuevos testimonios acerca de las legiones VI Victrix y X Gemina en la región septentrional de la Península Ibérica", [en] Deuxième congrès de Lyon sur l'armée romaine: Les legions de Rome sous le Haut-Empire, Lyon, 589-607.

(2006): "Legio (León). Introducción histórica y arqueológica", [en] M ${ }^{\mathrm{a}} \mathrm{P}$. García-Bellido (coord.), Los campamentos romanos en Hispania (27 a.C.-192 d.C.). El abastecimiento de moneda (=Anejos de Gladius 9), Madrid, 225-243

Morillo, A. - Pérez GonzÁlez, C. - Illarregui, E. (2006): “Asentamientos militares de Herrera de Pisuerga: introducción histórica y arqueológica”, [en] $\mathrm{M}^{\mathrm{a}} \mathrm{P}$. García-Bellido (ed.), Los campamentos romanos en Hispania (27 a.C.-192 d.C.). El abastecimiento de moneda, Madrid, 305-323.

Morillo, A. - SAlido, J. (2013): "Material constructivo latericio procedente del campamento de la legio VII gemina en León. La intervención arqueológica de Puerta Obispo", Lucentum (en prensa).

Neumann, A. (1973): Ziegel aus Vindobona (=Römische Limes in Österreich 27), Wien.

PALAO, J. J.

(1998): "Sobre el envío de tropas de la Legio VII Gemina al limes africano", Studia historica. Historia antigua 16, 149-172.

(2006): Legio VII Gemina (Pia) Felix. Estudio de una legión romana, Salamanca.

(2010): "On the concession of the title "Felix" to Legio VII Gemina", Athenaeum 90, II, 437-444.

Peacock, D. P. S. (1987): Pottery in the Roman world: an ethnoarchaeological report, London-New York.

Perestrelo, M. S. G.

(1998): "Marca de Oleiro do Manigoto", Ficheiro Epigráfico 71, no 315.

(2008): "Cidadelhe e a Proto-història e a Romanização de Médio Côa", [en] III Congreso de Arqueologia Tras-os-Montes, Alto Douro e Beira Interior, Porto, 56-71.

PÉrez GonzÁlez, C.

(1989): Cerámica romana de Herrera de Pisuerga (Palencia, España). La terra sigillata, Santiago de Chile.

(1996): "Asentamientos militares en Herrera de Pisuerga", [en] C. Fernández Ochoa (coord.), Los Finisterres atlánticos en la Antigüedad (época prerromana y romana), Gijón, 91-102.

Pérez González, C. - Illarregui, E. (2006): "Producciones militares en el campamento de la legio IIII Macedonica en Herrera de Pisuerga", [en] A. Morillo (ed.), Arqueología Militar Romana en Hispania. Producción y abastecimiento en el ámbito militar, León, 111-134. 
Petry, F. (1974): “Informations archéologiques. Circonscription d'Alsace. Biesheim”, Gallia 32, 373.

Radulescu, A. V. (1974): “Ateliers de produits en terre cuite le long du bas-Danube", [en] Actes IX Congrès Internationale d'Études Frontières romaines, Bucarest, 123-129.

Rico, CH.

(1999): "Éléments pour une approche socio-économique de la production de matériaux de construction en terre cuite dans les provinces hispaniques", [en] M. Bendala Galán - Ch. Rico - L. Roldán Gómez (eds.), El ladrillo y sus derivados en la época romana, Madrid, $25-44$.

(2000): "La production de briques et de tuiles dans la province romaine de Bétique. L'exemple de la vallée du Guadalquivir", [en] P. Boucheron - H. Broise - Y. Thébert (eds.), La brique Antique et médiévale. Production et commercialisation d'un matériau, Actes du colloque international organisé par le Centre d'histoire urbaine de l'École normale supériure de Fontenay/Saint Cloud et l'École française de Rome, Saint-Cloud, 16-18 novembre 1995, Roma, 177-192.

RitTERLING, E.

(1913): Das frührömische Lager bei Hofheim im Taunus, Verein für nassauische Altertumskunde und Geschichtsforschung, Wiesbaden.

(1925): "Legio", RE XII, 2, cols. 1214-1838.

Robles, J. M. (1997): “De Julióbriga a Octaviolca”, Cuadernos de Campóo 10, 13-22.

Rodríguez Colmenero, A. - Ferrer Sierra, E. (eds.), (2006): Excavaciones arqueológicas en Aquis Querquennis. Actuaciones en el campamento romano (1975-2005), (=Anejos de Larouco 4), Lugo.

Rodríguez GonzÁlez, J. (2001): Historia de las legiones romanas, Madrid.

RoldÁn GómEz, L. (2008): "El material constructivo latericio en Hispania. Estado de la cuestión”, [en] D. Bernal - A. Ribera (eds.), Cerámicas Hispanorromanas. Un estado de la cuestión, Cádiz, 749-773.

Roldán Hervás, J. M. (1974): Hispania y el ejército romano, Salamanca.

SPAUL, J.

(1994): Ala-2. The auxiliary cavalry Units of the Pre-Diocletian Imperial Roman Army, Andover. (2000): Cohors. The evidence for a short history of the auxiliary infantry units of the Imperial Roman Army (=BAR International Series 841), Oxford.

Spitzlberger, G. (1968): "Die römischen Ziegelstempel im nördlichen Teil der Provinz Raetien", Saalburg Jahrbuch 25, 65-184.

SteinBy, E. M. (1974-75): "La cronologia delle figlinae doliari urbane dalla fine del'età repubblicana fino all'inizio del III sec.", Bullettino della Commissione archeologica comunale di Roma 84, 7-132.

SzILAGYi, J. (1972): “Ziegelstempel”, RE XA, 2.19, 433-446.

Tsiolis, V. G. (1997): "Las restricciones de la producción tegularia en la Lex Ursonensis", Studia Historica. Historia Antigua 15, 119-136.

VAN DEN Eynde CERUTI, E. (1999): “Excavaciones arqueológicas en el yacimiento romano-medieval de Camesa-Rebolledo (Valdeolea, Cantabria)", [en] Regio Cantabrorum, Santander, 225-234.

WAHL, J. (1984): "Ein Ziegelstempel der legio X gemina aus dem Alenkastell bei Rosinos de Vidriales (Prov. Zamora)", Madrider Mitteilungen 25, 72-78.

WArry, P. (2010): “Legionary Tile Production in Britain”, Britannia 41, 127-147. 